\title{
Neuropathic Pain Creates an Enduring Prefrontal Cortex Dysfunction Corrected by the Type II Diabetic Drug Metformin But Not by Gabapentin
}

\author{
[Stephanie Shiers, Grishma Pradhan, Juliet Mwirigi, Galo Mejia, Ayesha Ahmad, Sven Kroener, and Theodore Price \\ University of Texas at Dallas, School of Behavioral and Brain Sciences, Richardson Texas 75080
}

Chronic pain patients suffer from pain-related cognitive deficits, even when taking commonly prescribed analgesics. These deficits are likely related to pain-related maladaptive plasticity in the frontal cortex. We sought to model cognitive deficits in mice with neuropathic pain to examine maladaptive morphological plasticity in the MPFC and to assess the effects of several therapeutics. We used an attentional set-shifting task in mice with spared nerve injury (SNI) who received either a single intrathecal injection of an analgesic dose of clonidine, $7 \mathrm{~d}$ of $100 \mathrm{mg} / \mathrm{kg}$ gabapentin, or $7 \mathrm{~d}$ of $200 \mathrm{mg} / \mathrm{kg}$ metformin. Male SNI mice were significantly more impaired in the set-shifting task than females. This deficit correlated with a loss of parvalbumin (PV) and reductions in axon initial segment (AIS) length in layers 5/6 of the infralimbic (IL) cortex. Acute pain relief with clonidine had no effect on set-shifting performance, whereas pain relief via 7 day treatment with gabapentin worsened the impairment in both SNI and sham mice. Gabapentin reversed the PV loss in the IL but had no effect on AIS length. Treatment with the AMPK-activator metformin completely reversed the pain-related cognitive impairment and restored AIS length in the IL but had little effect on PV expression. Our findings reveal that neuropathic pain-related cognitive impairments in male mice are correlated to bilateral morphological changes in PV interneurons and layer 5/6 IL pyramidal neuron AIS. Pain relief with metformin can reverse some of the functional and anatomical changes.

Key words: analgesics; axon initial segment; chronic pain; cognitive impairment; medial prefrontal cortex; metformin

Significance Statement

Cognitive impairments are a comorbidity of neuropathic pain but are inadequately addressed by existing therapeutics. We used a neuropathic pain model in mice to demonstrate that male (but not female) mice show a robust pain-related deficit in attentional set-shifting, which is associated with structural plasticity in axon initial segments in the infralimbic cortex. These deficits were completely reversed by 7 day treatment with the antidiabetic drug metformin, suggesting that this drug can be repurposed for the treatment of neuropathic pain and its cognitive comorbidities. Our findings have implications for our understanding of how neuropathic pain causes structural plasticity in the brain, and they point to a marked sexual dimorphism in neuropathic pain mechanisms in mice.

\section{Introduction}

Cognitive flexibility, the ability to recognize and react to new stimuli in the environment, is an executive function that depends

Received March 19, 2018; revised July 10, 2018; accepted July 13, 2018.

Author contributions: S.S., S.K., and T.P. edited the paper; S.S., G.P., S.K., and T.P. designed research; S.S., G.P., J.M., and G.M. performed research; S.S., G.P., J.M., and A.A. analyzed data; S.S. wrote the paper.

This work was supported by National Institutes of Health Grant R01NS065926 to T.P. and University of Texas STARS Program to T.P.

The authors declare no competing financial interests.

Correspondence should be addressed to either of the following: Dr. Theodore Price, University of Texas at Dallas, School of Behavioral and Brain Sciences, 800 West Campbell Road, BSB 14.102, Richardson, TX 75080, E-mail: Theodore.price@utdallas.edu; or Dr. Sven Kroener, University of Texas at Dallas, School of Behavioral and Brain Sciences, 800 West Campbell Road, BSB 10.514, Richardson, TX 75080, E-mail: Kroener@utdallas.edu. on areas in the frontal cortex in rodents and humans (Birrell and Brown, 2000; Heisler et al., 2015; Livingston-Thomas et al., 2015). Patients with chronic intractable pain (Eccleston, 1995; Dick et al., 2002; Karp et al., 2006; Schiltenwolf et al., 2014) and neuropathic pain (Ryan et al., 1993; Povedano et al., 2007; Attal et al., 2014) have poor performance in tasks that assess cognitive flexibility, suggesting that persistent pain disrupts normal cortical function. Importantly, currently prescribed analgesics are unable to reverse cognitive impairments, as these deficits persist and often worsen after analgesic treatment (Eccleston, 1995; Dick and Rashiq, 2007; Gálvez et al., 2007; Povedano et al., 2007; Schilten-

D0I:10.1523/JNEUROSCI.0713-18.2018

Copyright $\odot 2018$ the authors $\quad 0270-6474 / 18 / 387337-14 \$ 15.00 / 0$ 
A

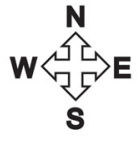

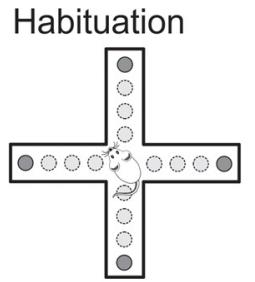

Response / Retest

(egocentric response, $\mathrm{L}$ or $\mathrm{R}$; ignore cue)
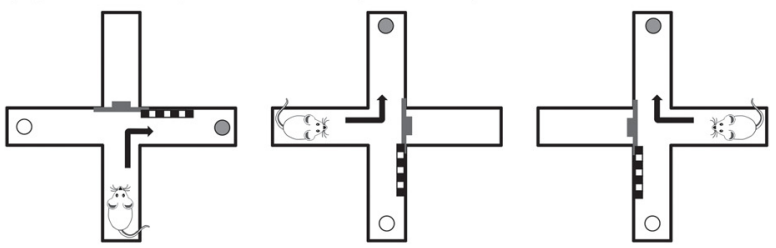

Set-shifting (turn towards visual cue)
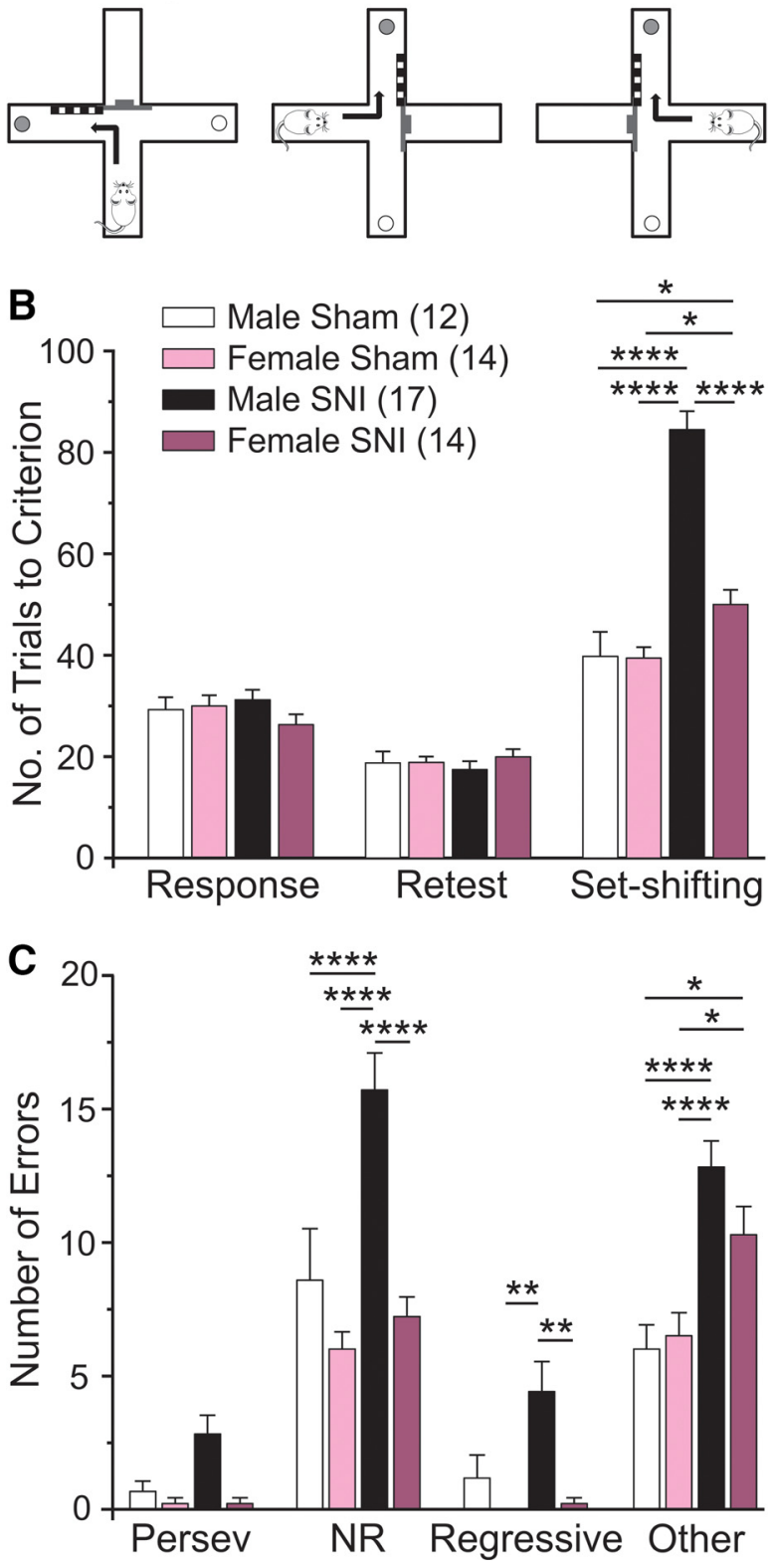

Figure 1. Neuropathic pain impairs cognitive flexibility with greater impairment in male than in female mice. $A$, Illustration of the attentional set-shifting protocol. Mice were habituated to the maze over $3 \mathrm{~d}$. On day 4 , mice were assessed for preference to turn right or left over wolf et al., 2014). As such, there is a great need for pain medicines that are capable of permanently alleviating pain and its associated cognitive comorbidities. The discovery of such therapeutics would have a great impact on clinical care. However, progress in this area is impeded by a lack of robust preclinical behavioral testing paradigms that can assess such comorbidities in neuropathic pain (Urban et al., 2011; Sheahan et al., 2017).

The $\mathrm{mPFC}$ undergoes morphological and functional reorganization during chronic pain. For instance, laminar-specific changes in the length of dendrites and spine densities occur in rodents with neuropathic pain (Metz et al., 2009; Kelly et al., 2016). Moreover, in arthritis and neuropathic pain models, enhanced glutamatergic inputs to the MPFC from the BLA cause augmented feedforward inhibition by GABAergic interneurons, thus reducing pyramidal neuron excitability (Ji et al., 2010; Ji and Neugebauer, 2011; Zhang et al., 2015). Optogenetic activation or inhibition of parvalbumin (PV)-positive GABAergic interneurons in neuropathic mice causes an increase or decrease, respectively, in mechanical hypersensitivity, suggesting that these cells may be directly involved in sensory processing of chronic pain (Zhang et al., 2015). In other disease models, a loss of PV expression in the $\mathrm{mPFC}$ has also been linked to deficits in cognitive flexibility (Murray et al., 2015; Zhou et al., 2015; Hashemi et al., 2017), increased GABA release, abnormal spike timing, disrupted inhibition, and asynchronous gamma wave oscillations (Vreugdenhil et al., 2003; Volman et al., 2011; Petitjean et al., 2015; Filice et al., 2016). Recent studies have also demonstrated that sensory experience can impact axon initial segments (AISs) in cortical regions (Grubb and Burrone, 2010; Kuba et al., 2010; Grubb et al., 2011; Leterrier, 2018), but this has not been studied in the context of neuropathic pain. While advances have been made in understanding $\mathrm{mPFC}$ dysfunction during chronic pain, important gaps in our knowledge persist. These include linking these anatomical and functional changes to behavioral signs of known comorbidities in neuropathic animals and investigating how analgesics influence this dysfunction.

Our primary goal was to measure impairments in cognitive flexibility in mice with neuropathic pain induced by spared nerve injury (SNI). To do this, we used a mPFC-dependent attentional set-shifting task (Jeevakumar et al., 2015) and found major deficits in set-shifting behavior in SNI mice. We hypothesized that neither acute nor systemic treatment with existing therapeutics would be sufficient to alleviate cognitive dysfunction in SNI mice. In contrast, we predicted that metformin, an antidiabetic drug that activates adenosine monophosphate-activated protein $\mathrm{ki}$ nase (AMPK) and causes relief of nociceptive behaviors in mice (Melemedjian et al., 2011; Melemedjian and Khoutorsky, 2015; Burton et al., 2017), would be able to restore normal cognitive function. A secondary objective was to identify morphological changes in the mPFC that may contribute to the cognitive dysfunction. Therefore, we examined PV expression and AIS length

$\leftarrow$

7 trials (Turn bias). The following day, mice were trained to turn against their turn bias to retrieve food reward and to ignore the pseudorandomly placed visual cue (Response). Approximately 3 weeks after SNI, the animals were assessed for retention of the task (Retest). The next day, mice were trained to shift strategies so that they now had to turn toward the arm containing the visual cue to obtain food reward (Set-shifting). B, Male and female SNI mice showed no impairment on retest day, indicating that $\mathrm{SNI}$ had no negative effect on retention of response training. In contrast, male and female SNI mice required significantly more trials to reach criterion on set-shifting day with males requiring significantly more trials than females. $C$, Male SN mice made significantly more NRE and RE compared with female SNI mice. Two-way ANOVA with Bonferroni multiple comparisons: ${ }^{* * *} p<0.0001 ;{ }^{* *} p<0.01 ;{ }^{*} p<0.05$. 
in mice with neuropathic pain with and without drug treatment. Our findings support the conclusion that cognitive dysfunction in neuropathic pain can be rescued with metformin treatment and that this effect is accompanied by a restoration of AIS maladaptive plasticity.

\section{Materials and Methods}

Animals

C57BL/6J wild-type mice (Taconic Biosciences) at 12 weeks of age were used for the experiments. All behavioral experiments were performed in male mice, except for a single sex difference experiment that used female mice. Histology experiments were conducted in both male and female mice.

Upon arrival, animals were housed on a $12 \mathrm{~h}$ light/dark cycle and had food and water available ad libitum. One week later, animals were separated and individually housed for experiments involving food restriction (attentional set-shifting). All procedures were performed during the light cycle. All experiments were approved by the Institutional Animal Care and Use Committee at the University of the Texas at Dallas and conducted in accordance with the National Institutes of Health and International Association for the Study of Pain guidelines.

\section{Surgery}

SNI was performed by cutting the tibial and peroneal branches of the left sciatic nerve trifurcation, leaving the sural branch intact as described previously (Decosterd and Woolf, 2000). Sham surgery was done in the same way but without cutting the nerve. Mice were allowed to recover for 2 weeks following surgery.

\section{Mechanical withdrawal threshold}

Tactile sensitivity was measured by probing the left outer surface of the left hindpaw with a series of calibrated von Frey filaments. Withdrawal thresholds were calculated using the up-down method (Chaplan et al., 1994). Mechanical withdrawal thresholds were assessed in all animals before and after (2 weeks) SNI to confirm neuropathy and at later time points to assess relief of mechanical hypersensitivity.

\section{Drugs}

Metformin hydrochloride (M2076, LKT Laboratories) was administered intraperitoneally (i.p.) at $200 \mathrm{mg} / \mathrm{kg}$ once daily for $7 \mathrm{~d}$ as previously reported (Melemedjian et al., 2011). Before the experiment, doseresponse curves assessing motor function (rotarod) and mechanical withdrawal thresholds were generated for gabapentin (PHR1049, SigmaAldrich) to determine a dosage that gave the longest duration relief of mechanical hypersensitivity without motor impairment. Motor function was assessed using a rotarod (IITC Life Science, rotarod series 8) with ramp speed (20 rpm acceleration) at a starting speed of $4 \mathrm{pm}$ for a maximum of $90 \mathrm{~s}$ as previously described (Deacon, 2013). For set-shifting, a $100 \mathrm{mg} / \mathrm{kg}$ dose of gabapentin was given intraperitoneally twice daily for $7 \mathrm{~d}$. A single intrathecal (i.t.) injection of clonidine was administered at $10 \mu \mathrm{g} / 5 \mu \mathrm{l}$. All drugs were dissolved in $0.9 \%$ sterile saline.

\section{Attentional set-shifting}

Attentional set-shifting was performed as previously described (Hu et al., 2015; Jeevakumar et al., 2015).

Habituation. Mice were handled and gradually food restricted to $90 \%$ of their baseline weight over 3 weeks. Habituation took place over $3 \mathrm{~d}$ in which food rewards (Cheerio bits) were placed along each arm of a plus maze. Mice were allowed to freely explore the maze and consume the food for 4 trials per day with a maximum time of $30 \mathrm{~min}$ per trial. When the mouse had consumed all of the food, the trial ended, and the mouse was returned to a holding cage while the maze was rebaited. The number of food pellets in each arm decreased from 4 to 2 to 1 on each consecutive day of habituation.

Turn bias. On the fourth day, we assessed the animals' turn bias. Therefore, the plus maze was converted into a T maze by blocking off one of the arms. Mice were placed in the stem arm (starting arm) and allowed to turn left or right to obtain a food pellet (compare Fig. 1A). After the mouse consumed the reward, it was returned to the stem arm and al-
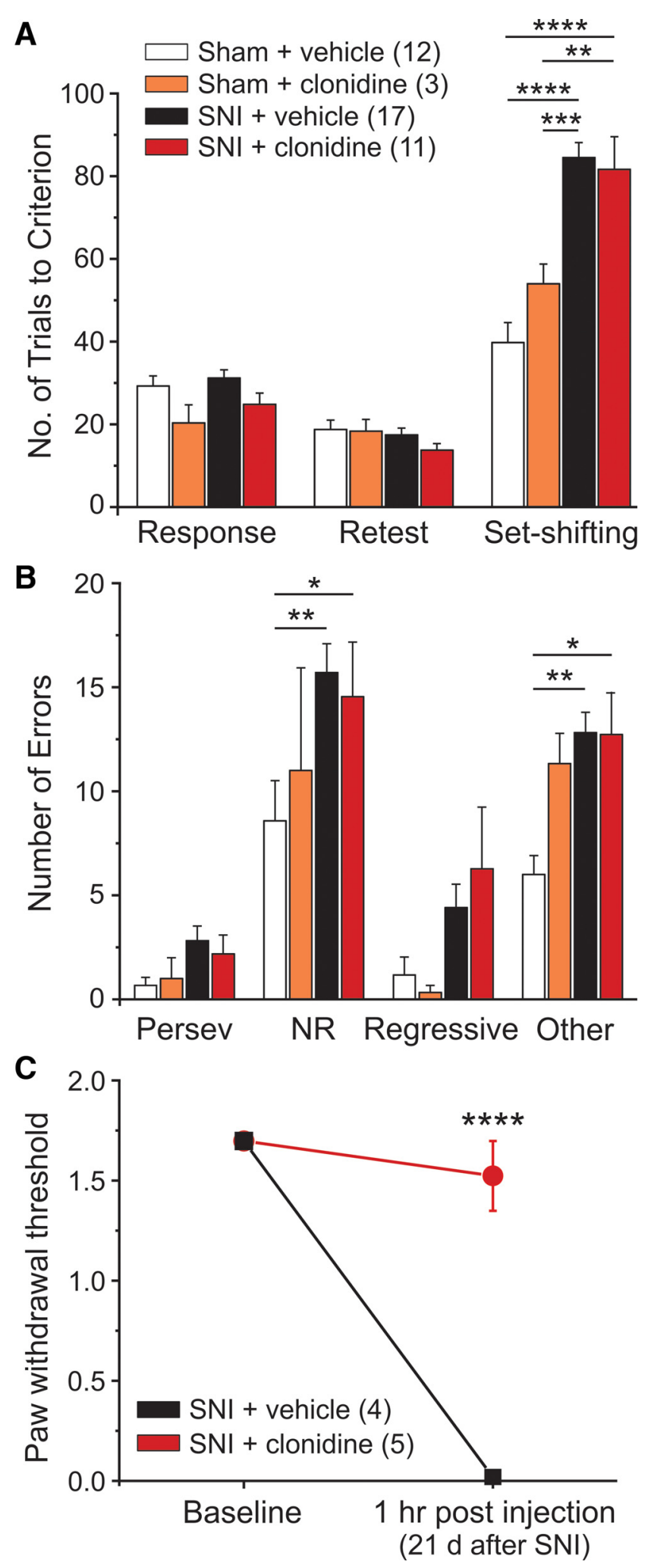

Figure 2. Clonidine-induced acute analgesia has no effect on the pain-related impairment in cognitive flexibility. $\boldsymbol{A}$, SNI mice treated with clonidine (10 $\mu \mathrm{g}$ i.t.) $1 \mathrm{~h}$ before set-shifting showed no differences in set-shifting performance compared with vehicle-treated SNI animals. $\boldsymbol{B}$, SNI vehicle and clonidine-treated animals made significantly more NRE and OE type errors compared with vehicle-treated sham controls. C, SNI mice received either vehicle or clonidine (10 $\mu \mathrm{g}$ i.t.) and were tested $1 \mathrm{~h}$ later for mechanical hypersensitivity. Two-way ANOVA with Bonferroni multiple comparisons: ${ }^{* * *} p<0.0001 ;{ }^{* * *} p<0.001 ;{ }^{* *} p<0.01 ;{ }^{*} p<0.05$. 

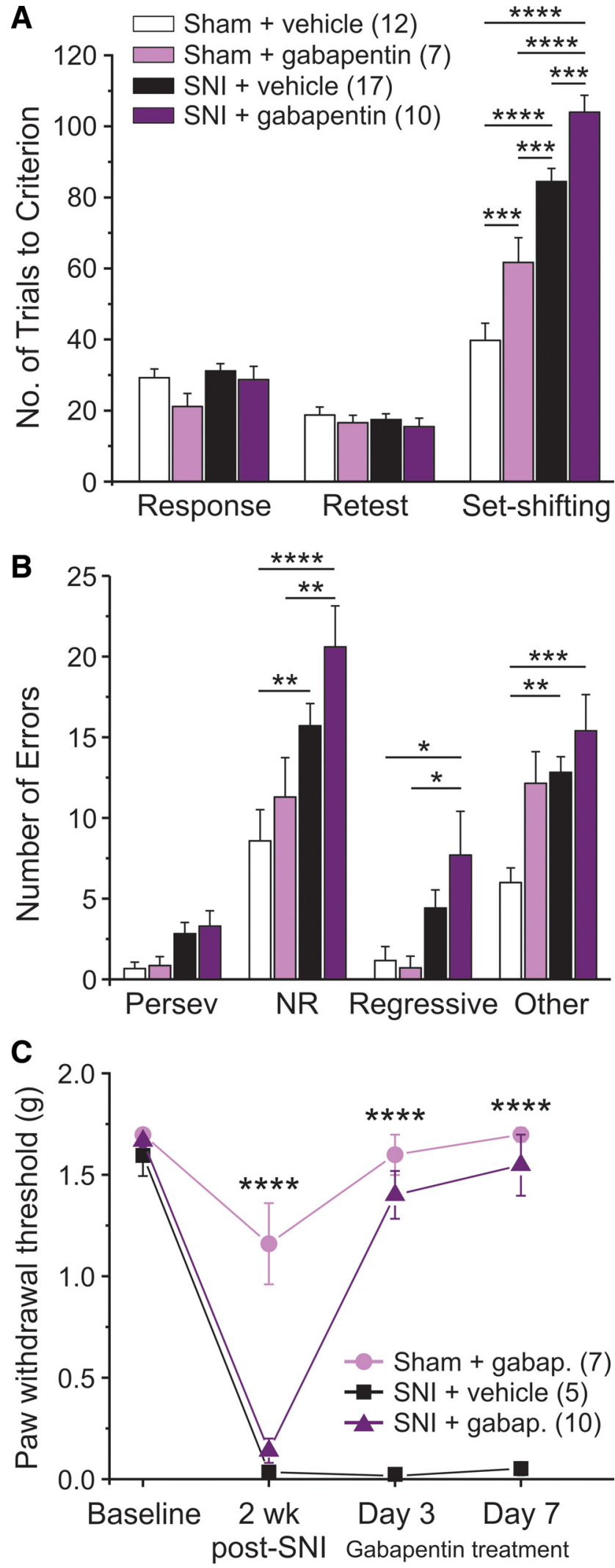

Figure 3. Pain relief with gabapentin worsens attentional set-shifting performance in SNI and sham mice. $\boldsymbol{A}$, Gabapentin was administered twice daily $(100 \mathrm{mg} / \mathrm{kg})$ for $7 \mathrm{~d}$, a dose determined to alleviate tactile allodynia without impairing motor function (Figure 3-1, available at https://doi.org/10.1523/JNEUROSCI.0713-18.2018.f3-1). The last injection was delivered 1 $h$ before set-shifting. Gabapentin significantly impaired SNI- and Sham-treated animals. B, SNI animals treated with gabapentin made significantly more NRE, RE, and OE compared with vehicle-treated sham controls. C, Gabapentin reversed mechanical (Figure legend continues.) lowed to make another choice. If the mouse chose the same arm as on the initial choice, it was returned to the stem arm until it chose the other arm and consumed the food pellet. The direction of the initial turn chosen four or more times over seven trials was considered the turn bias.

Response discrimination. On the next day, mice were trained on a response discrimination task that required them to always turn into one arm (left or right, chosen opposite to the direction of their turn bias) to obtain the food reward. The location of the stem arm (starting arm) was pseudorandomly alternated among 3 arms (east, west, and south) to prevent mice from using an allocentric spatial strategy to locate the food. A visual cue was placed close to the entrance of one of the choice arms. Placement of this cue into the right or left arm varied pseudorandomly to balance the frequency of occurrences in each arm across blocks of 12 consecutive trials. Similarly, the order of the stem arms alternated pseudorandomly in a balanced fashion across blocks of 12 trials. Training continued until the mouse made 9 correct choices over 10 consecutive trials, or up to a maximum of 200 trials. When animals achieved this acquisition criterion, a probe trial was administered. In the probe trial, the previously unused stem arm (north) was used as the starting arm. If the mice performed the probe trial correctly, response discrimination training was completed. If an incorrect turn occurred, response training continued until the mouse made another five consecutive correct choices, and then another probe trial was administered. Upon completion, the total number of trials was tallied, and animals were sorted into counterbalanced groups based on response values. SNI or sham surgeries were then conducted, followed by a 2 week recovery period. After the 2 week surgical recovery period, a subset of mice was given metformin (once daily for $7 \mathrm{~d}$ ), gabapentin (twice daily for $7 \mathrm{~d}$ ), or clonidine (single injection delivered $1 \mathrm{~h}$ before set-shifting).

Retest. Approximately 3 weeks after surgery, the mice were tested for retention of the response discrimination strategy. Retest day was a repeat of the response discrimination training day and took place on the last day of metformin treatment (day 21 after surgery), on day 6 of gabapentin treatment (day 20 after surgery), and the day before clonidine treatment (day 20 after surgery).

Shift-to-visual-cue discrimination. On the final day, mice were trained to shift their strategy to now follow the visual cue to obtain food rewards. The location of the visual cue and the position of the start arm were again varied pseudorandomly so that their frequency was balanced across blocks of 12 consecutive trials. The training and response criteria for the shift-to-visual-cue discrimination were identical to those during response discrimination. Gabapentin (day 7 of treatment; day 21 after surgery) or clonidine (day 21 after surgery) was delivered $1 \mathrm{~h}$ before set-shifting. Animals were timed while undergoing set-shifting to account for any differences in locomotor or motivational behaviors due to analgesic treatment.

Performance and error analysis. For each of the two test days, we analyzed the total number of trials to criterion and the number of probe trials required to reach criterion. For the shift-to-visual-cue discrimination, errors were scored as entries into arms that did not contain the visual cue, and they were further broken down into three subcategories to determine whether the animals' treatment altered the ability to either shift from the previously learned strategy (perseverative errors [PEs]), or to maintain the new strategy after perseveration had ceased (regressive errors [REs], or never-reinforced errors [NREs]). To detect shifts in the strategies animals used, trials were separated into consecutive blocks of four trials each. A PE occurred when a mouse made the same egocentric response as required during the response discrimination, but which was opposite to the direction of the arm containing the visual cue. Six of every 12 consecutive trials required the mouse to respond in this manner. A PE was scored when the mouse entered the incorrect arm on three or more trials per block of 4 trials. Once the mouse made fewer than three PEs in a block, all subsequent errors of the same type were now scored as REs

(Figure legend continued.) withdrawal thresholds when tested on days 3 and 7 of its 7 day administration period. Two-way ANOVA with Bonferroni multiple comparisons: ${ }^{* * *} p<$ $0.0001 ;{ }^{* * *} p<0.001 ;{ }^{* *} p<0.01 ;{ }^{*} p<0.05$. 
because at this point the mouse was following an alternative strategy at least half of the time. So-called NREs were scored when a mouse entered the incorrect arm on trials where the visual cue was placed on the same side that the mouse had been trained to enter on the previous day. Other error $(\mathrm{OE})$ types were scored when the mouse made an error that did not fit a PE, RE, or NRE pattern. Together, these error types provide insight into whether SNI and/or analgesics alter the ability of animals to shift strategies (PE) and/or to maintain the new strategy (NRE, RE).

Experimental design and data presentation. All set-shifting experiments were done on cohorts of male and female animals that were run over the course of 12 months. For male animals, there were -8 treatment groups: SNI + vehicle (i.p. injection), SNI + clonidine, SNI + metformin, SNI + gabapentin and sham + vehicle, sham + clonidine, sham + metformin, sham + gabapentin. Animals in each group were staggered, and groups were run in a balanced manner. The SNI + vehicle and sham + vehicle groups are shown in each figure for comparison with drug-treated groups.

\section{Immunohistochemistry}

All mice were perfused at 3 weeks after surgery (the day after analgesic treatment and/or set-shifting) except for one additional group of metformin and vehicle-treated animals that were perfused $14 \mathrm{~d}$ after treatment ( 5 weeks after surgery). Mice were deeply anesthetized with a mixture of ketamine $(80 \mathrm{mg} / \mathrm{kg})$ and xylazine $(12 \mathrm{mg} / \mathrm{kg}$; i.p.) and then transcardially perfused with $1 \times \mathrm{PBS}\left(4^{\circ} \mathrm{C}, \mathrm{pH} 7.4\right)$ followed by $10 \%$ formalin in $0.1 \mathrm{M}$ phosphate buffer $\left(\mathrm{PB} ; 4^{\circ} \mathrm{C}, \mathrm{pH}\right.$ 7.4) using a perfusion pump. Flow rate $(5 \mathrm{ml} / \mathrm{min})$ and perfusion time $(\sim 5 \mathrm{~min})$ were carefully controlled so that each animal received $25 \mathrm{ml}$ of fixative. Brains were postfixed in $10 \%$ formalin for $1 \mathrm{~h}$ and then transferred to a $10 \%$ sucrose in $0.1 \mathrm{~m}$ PB solution. Once the brains sunk in $10 \%$ sucrose, they were transferred to a $30 \%$ sucrose in $0.1 \mathrm{M}$ PB. A needle was then placed through the length of the left side of the brain to demarcate the left (ipsilateral to SNI) hemisphere. Brains were then placed in an embedding mold (Thermo Fisher Scientific; 18-30), immersed in OCT, and frozen over dry ice. Coronal sections $(30 \mu \mathrm{m})$ were cut using a cryostat and collected in serial order in a 12-well plate containing $0.1 \mathrm{M}$ PB. Free floating sections were then washed in $0.1 \mathrm{M} \mathrm{PB}$ and then incubated in blocking solution ( $10 \%$ normal goat serum, $0.3 \%$ Triton X-100 in $0.1 \mathrm{M}$ $\mathrm{PB})$ for $1 \mathrm{~h}$ at room temperature with gentle rocking/agitation. Sections were incubated in primary antibodies diluted in blocking solution for $3 \mathrm{~h}$ at room temperature. The primary antibodies used were as follows: rabbit-anti-PV (Swant, catalog \#PV 25 RRID:AB_10000344; 1:2000 working dilution) and mouse-anti-ankyrin-G (University of CaliforniaDavis/National Institutes of Health NeuroMab Facility, clone N106/36 RRID:AB_10673030; $2 \mu \mathrm{g} / \mathrm{ml}$ working concentration). Sections were washed 5 times in $0.1 \mathrm{M} \mathrm{PB}$ and then incubated in secondary antibody (1:2000 each) diluted in blocking solution containing DAPI (1:5000 working dilution) for $1 \mathrm{~h}$ at room temperature. The secondary antibodies used were as follows: goat-anti-rabbit $555 \mathrm{H} \& \mathrm{~L}$ (Thermo Fisher Scientific, A21429) and goat-anti-mouse 488 IgG2a (Thermo Fisher Scientific, A21131). Following secondary incubation, sections were washed 5 times in $0.1 \mathrm{M} \mathrm{PB}$, mounted onto glass slides, coverslipped using Prolong Gold Antifade (Thermo Fisher Scientific, P36930), and sealed with nail polish once cured.

\section{Image analysis}

$P V$. A low-magnification $(2 \times)$ image of each section was first acquired using an Olympus slide scanner (VS120). Section morphology was compared with the mouse brain atlas (Franklin and Paxinos, 2008) and boundaries were then drawn (the same size) around the dorsal anterior cingulate (Cg1), prelimbic (PrL), and infralimbic (IL) cortices, and a minimum of 3 images at $20 \times$ magnification were acquired for each region and for each animal. All images were converted to tiff format with randomized file names (for blinding) and analyzed in ImageJ. PVpositive cells were manually counted using the cell counter tool, and DAPI was auto-counted using the "analyze particles" feature. Ratios (PV/ total DAPI) were calculated, averaged (3 images per animal), and normalized to the sham condition.

AIS-ankyrin-G antibody. A minimum of $3 z$-stacked images of Cg1, $\mathrm{PrL}$, and IL were acquired at $40 \times$ magnification for each animal using an
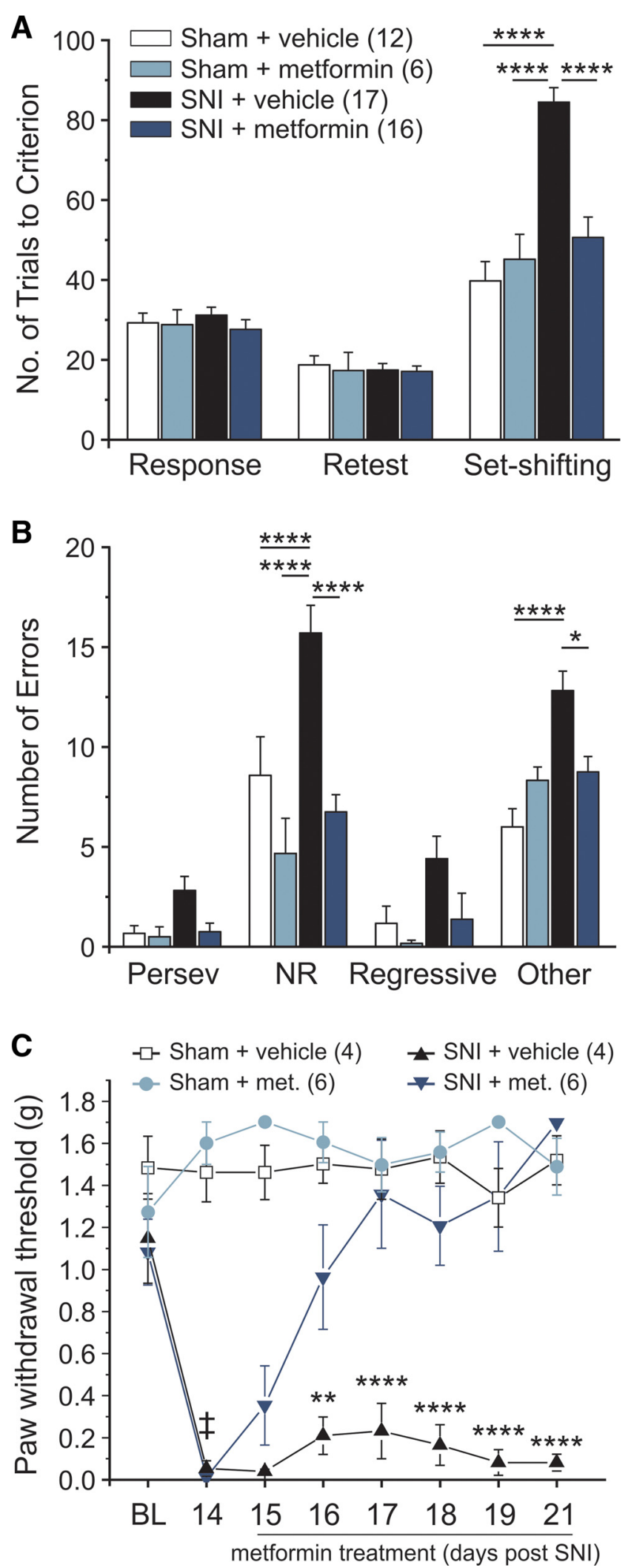

Figure 4. Metformin reverses pain-related impairment in cognitive flexibility. $\boldsymbol{A}$, Metformin delivered once daily ( $200 \mathrm{mg} / \mathrm{kg}$ i.p.) for $7 \mathrm{~d}$ completely reversed the pain-related deficit in set-shifting performance. $\boldsymbol{B}$, Metformin-treated SNI animals made significantly less NRE and OE compared with SNI vehicle-treated controls and performed similarly to sham animals. C, Metformin reverses mechanical hypersensitivity with $7 \mathrm{~d}$ of daily injections. Two-way ANOVA with Bonferroni. Significant comparisons between the SNI vehicle group and the SNI metformin group: ¥SNI + veh and SNI + metformin. Significantly different compared with sham controls: ${ }^{* * * *} p<0.0001 ;{ }^{* *} p<0.01 ;{ }^{*} p<0.05$. 
A

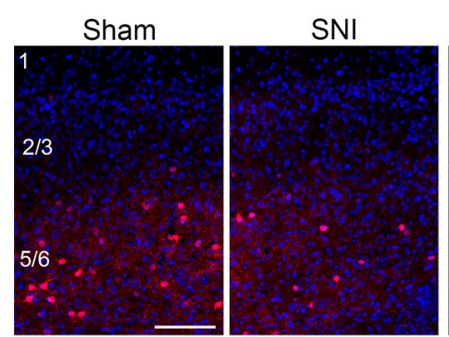

ipsilateral

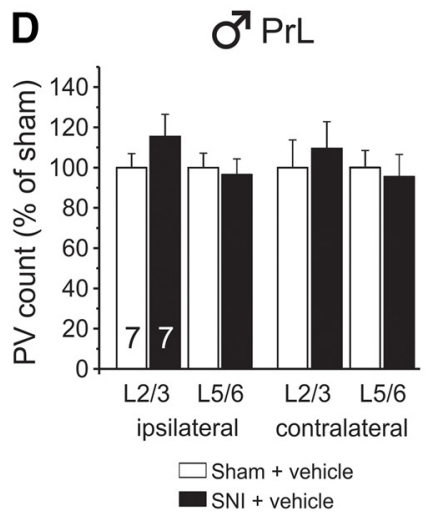

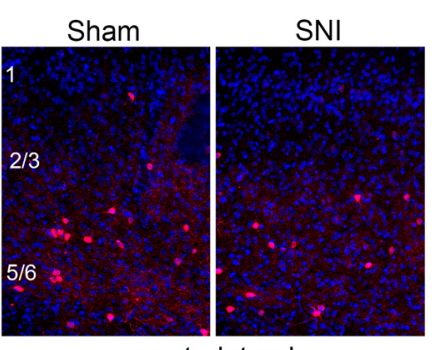

contralateral

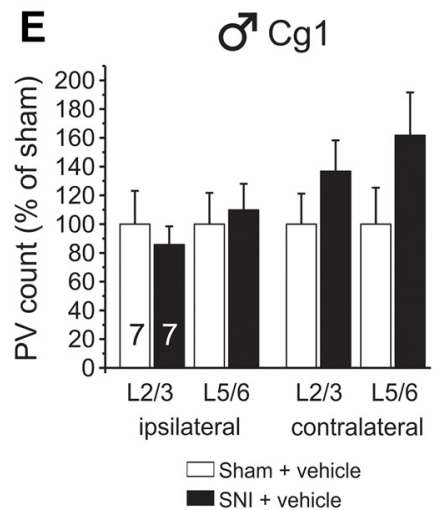

B

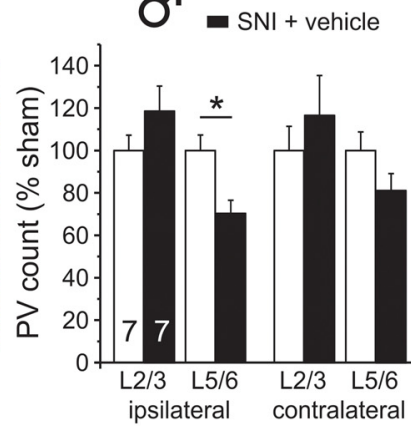

C

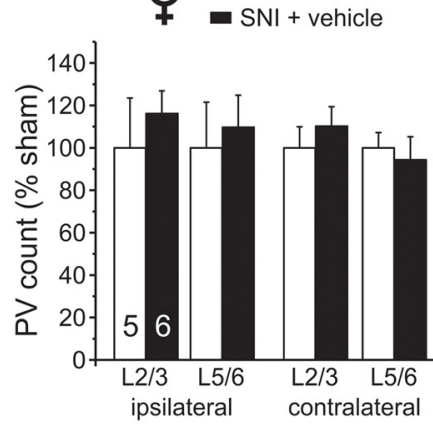

F $\quad \sigma^{\top}$ IL layer $5 / 6$

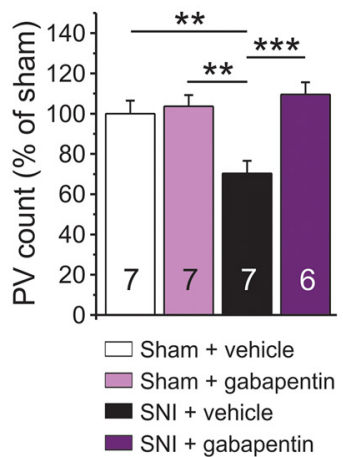

G

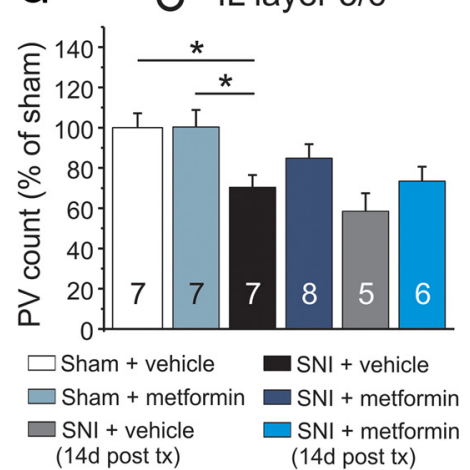

Figure 5. PV expression is reduced in the ipsilateral IL of SNI mice. $\boldsymbol{A}$, Representative $20 \times$ images showing PV loss in the IL of SNI male mice. $\boldsymbol{B}$, Male SNI mice showed a significant loss of PV in the IL ipsilateral to injury (left hemisphere), which was confined to cortical layers 5/6. C, Female SNI mice showed no PV loss in the IL. The PrL (D) and Cg1 (E) cortices showed no loss in PV. $\boldsymbol{F}$, Gabapentin treatment ( $100 \mathrm{mg} / \mathrm{kg}$ twice daily for $7 \mathrm{~d}$ ) reversed the PV loss in male SNI mice. G, Metformin treatment ( $200 \mathrm{mg} / \mathrm{kg}$ once daily for $7 \mathrm{~d}$ ) had no effect on PV loss. This effect was not dependent on when the tissue was collected: 1 or $14 \mathrm{~d}$ after treatment (tx). One- or two-way ANOVA with Bonferroni with all groups compared with the SNI + vehicle group: ${ }^{* * *} p<0.001$; ${ }^{* *} p<$ $0.01 ;{ }^{*} p<0.05$.

Olympus confocal microscope (FV1200). Images were converted to tiff format with randomized file names (for blinding). For each image, 30 segments were analyzed in layers $2 / 3$ and layers 5/6 in CellSens (Olympus) using the polyline measure tool. Length measurements were averaged ( 3 images per animal); $100 \times$ images are also shown in the figures.

\section{Data analysis and statistics}

Graphs and statistical analyses were generated using Prism version 7.01 (GraphPad Software). Statistical differences between groups were assessed using one- and two-way ANOVAs with Bonferroni as indicated in the text and figure captions. Because of the double normalization of the PV effect (once to DAPI, and once to the Sham condition), we chose to analyze each hemisphere individually, whereas the raw AIS data are analyzed together. Comparisons between each treatment and the SNI + vehicle group are shown. All statistics, including $F$ and exact $p$ values, are shown in Tables 1, 2, 3, and 4. All data are represented as mean \pm SEM, with $p<0.05$ considered significant. Sample sizes are displayed in the graphs of each figure. The raw data files can be found at www.utdallas.edu/bbs/painneurosciencelab/projects/PFC_pain/.

\section{Results}

SNI causes a significant impairment in attentional set-shifting performance that is greater in males than in females

We used an attentional set-shifting task (Fig. 1A) to investigate cognitive impairments that occur in the mouse SNI model of persistent neuropathic pain. Male and female mice showed no differences on retest day, indicating that surgery had no effect on retention of response training (Fig. 1B). SNI significantly impaired the ability of both male and female mice to switch strategies in the attentional set-shifting task (Fig. 1B). Male SNI mice made significantly more NREs, REs, and OEs compared with male sham controls, suggesting there was a deficit in the mainte- nance of the new strategy (Fig. 1C). Females made significantly more OEs compared with female sham controls (Fig. 1C). Unexpectedly, we observed a strong sexual dimorphism in the cognitive effects of neuropathic pain. Female SNI mice were impaired in the attentional set-shifting task compared with female sham controls but required significantly fewer trials to reach criterion compared with male SNI mice (Fig. $1 B$ ). In addition, female SNI mice made significantly fewer NREs and REs compared with male SNI mice (Fig. 1C). Given the robust effect of pain on attentional set-shifting performance in male mice, we chose to continue our behavioral studies in male animals.

\section{Acute analgesia with clonidine fails to reverse deficits in} attentional set-shifting induced by neuropathic pain

Next, we assessed the effects of acute pain relief with clonidine on set-shifting performance. We chose clonidine because this drug is an effective acute analgesic in humans; and when given intrathecally to rodents, it promotes relief of mechanical hypersensitivity and spontaneous pain (King et al., 2009) through an action on $\alpha_{2}$-adrenergic receptors (Wilcox et al., 1987). All groups showed similar behaviors on retest day (Fig. $2 A$ ), indicating that surgery had no effect on retention of response training. Clonidine was administered $1 \mathrm{~h}$ before the start of set-shifting at a dose of 10 $\mu \mathrm{g} / 5 \mu \mathrm{l}$. In a subset of mice, we empirically verified that this dose completely alleviates mechanical hypersensitivity over the time course of the set-shifting experiment (Fig. 2C). Clonidine had no effect on set-shifting performance (Fig. 2A). Vehicle- and clonidinetreated SNI animals made significantly more NREs and OEs compared with sham controls (Fig. 2B). 


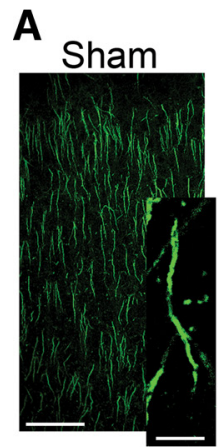

ipsilateral

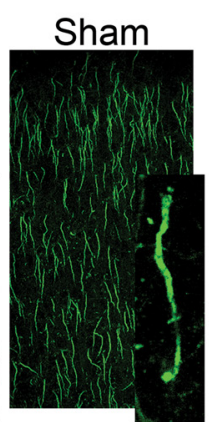

contralateral

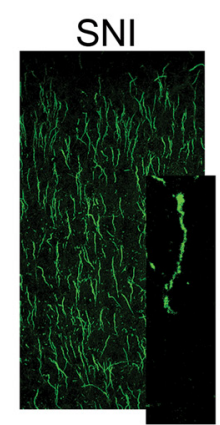

ipsilateral

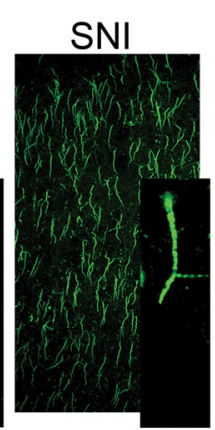

contralateral

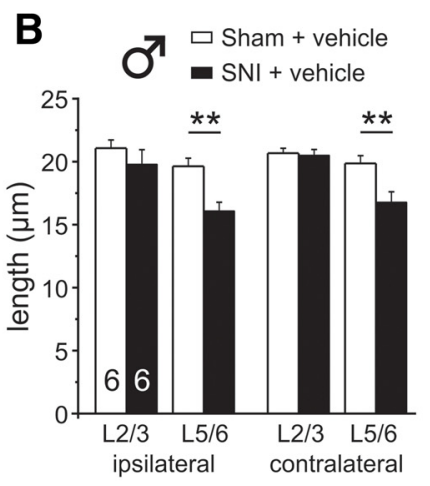

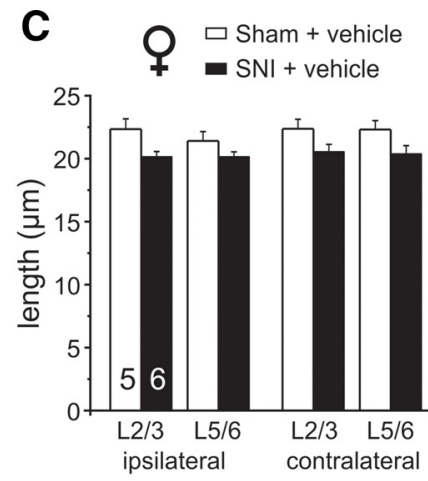

D

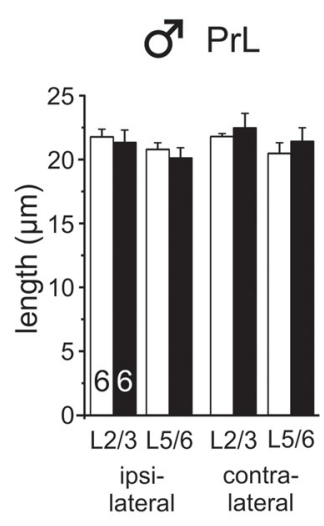

E
$\mathbf{F}$ $\sigma^{7}$ IL layer $5 / 6 \quad$ G $\sigma^{7} \mathrm{Cg} 1$

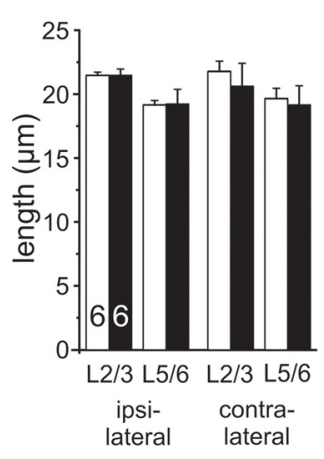

lateral lateral

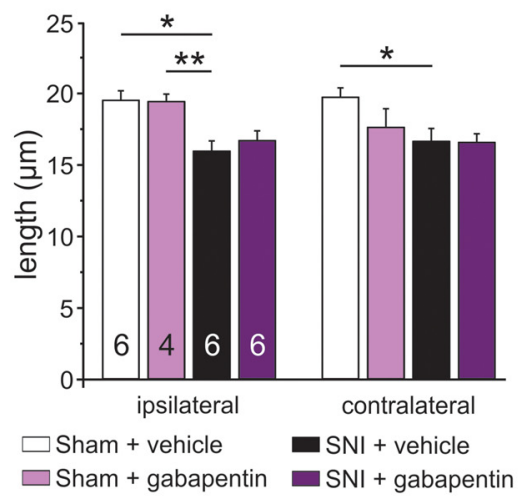

IL layer $5 / 6$

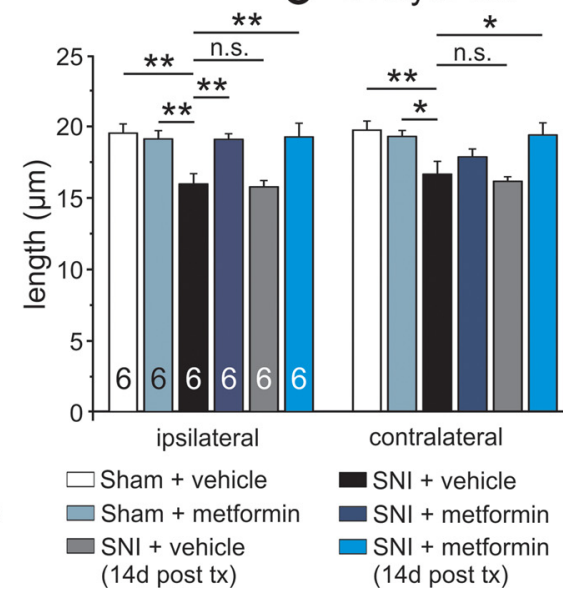

Figure 6. SNI causes a reduction in AIS length in the IL, an effect that is partially reversed by metformin. $\boldsymbol{A}$, Representative $40 \times$ and $100 \times$ images showing AIS staining in the IL. $\boldsymbol{B}$, Male SNI mice had significantly shorter AISs in the ipsilateral and contralateral IL, which was confined to cortical layers 5/6. C, Female SNI mice did not show a significant reduction in AIS length in the IL. There were no changes observed in AIS length in the PrL $(\boldsymbol{D})$ or $\boldsymbol{C g} 1(\boldsymbol{E})$ subregions of male SNI mice. $\boldsymbol{F}$, Gabapentin treatment had no effect on AIS length in the IL. $\boldsymbol{G}$, Metformin treatment reversed the loss in the ipsilateral IL, but not contralateral IL, when assessed $1 \mathrm{~d}$ after treatment but reversed it in both hemispheres when assessed $14 \mathrm{~d}$ after treatment. Two-way ANOVA with Bonferroni with all groups compared with the SNI + vehicle group: ${ }^{* *} p<0.01 ;{ }^{*} p<0.05$.

Pain relief by gabapentin does not reverse, but further impairs, pain-related deficits in attentional set-shifting performance

Gabapentin was delivered systemically twice daily (injections in the morning and evening) for $7 \mathrm{~d}$ to assess the effects of gabapentin on cognitive function. Gabapentin dose-response curves for tactile allodynia and motor behavior on the rotarod were generated before experimentation and revealed that a single injection of $100 \mathrm{mg} / \mathrm{kg}$ gabapentin improved mechanical withdrawal thresholds for $\sim 6.5 \mathrm{~h}$ and had no effect on motor coordination (Fig. 3-1, available at https://doi.org/10.1523/ JNEUROSCI.0713-18.2018.f3-1). In the set-shifted gabapentin mice, mechanical withdrawal thresholds were measured on days 1, 3, 6 (retest day), and 7 (set-shifting day) $\sim 1 \mathrm{~h}$ after the first injection of that day. Retest took place on day 6 of gabapentin treatment, and no differences between groups were found at this time point (Fig. 3A). The final dose of gabapentin was delivered $\sim 1 \mathrm{~h}$ before set-shifting. Sham and SNI animals treated with gabapentin were significantly more impaired in the attentional set-shifting task than vehicle-treated controls (Fig. 3A). SNI animals treated with gabapentin made significantly more NREs, REs, and OEs, indicating that they had difficulties in maintaining the new strategy (Fig. 3B). Gabapentin treatment completely reversed mechanical hypersensitivity at all four time points tested (Fig. 3C). Therefore, although gabapentin led to a robust antino- ciceptive effect, it failed to reduce deficits in cognitive flexibility and induced deficits on its own in sham mice.

Metformin treatment reverses pain-induced impairments in attentional set-shifting performance

The clinically used AMPK activator metformin was delivered once daily for $7 \mathrm{~d}$ to achieve reversal of persistent neuropathic pain, as we have previously shown (Melemedjian et al., 2011, 2013). There were no differences between groups on retest day (Fig. $4 A$; final day of metformin treatment). Metformin-treated SNI animals showed a significant reduction in the number of trials to criterion compared with the SNI-vehicle group (Fig. 4A). Metformin also reduced the number of errors to levels of shamtreated animals (Fig. 4B) and completely reversed SNI-induced mechanical hypersensitivity (Fig. 4C). Thus, in contrast to a single intrathecal dose of clonidine or $7 \mathrm{~d}$ of systemic dosing with gabapentin, $7 \mathrm{~d}$ systemic dosing with metformin reversed paininduced cognitive impairment in male mice.

Persistent neuropathic pain reduces PV expression in the left infralimbic subregion of the $\mathrm{MPFC}$, which is reversed by gabapentin treatment

Alterations in the excitation-inhibition balance affect mPFCdependent behaviors, including attentional set-shifting (Phensy et al., 2017a,b). PV-expressing interneurons represent a signifi- 
Table 1. Two-way ANOVA

\begin{tabular}{|c|c|c|c|c|c|c|c|c|c|c|}
\hline \multirow[b]{2}{*}{ Figure } & \multirow[b]{2}{*}{ Panel } & \multicolumn{3}{|c|}{ Source of variation surgery/treatment } & \multicolumn{3}{|c|}{ Time/day, location, or error type } & \multicolumn{3}{|c|}{ Interaction } \\
\hline & & $\mathrm{dfn}, \mathrm{dfd}$ & $F$ & $p$ & $\mathrm{dfn}, \mathrm{dfd}$ & $F$ & $p$ & $\mathrm{dfn}, \mathrm{dfd}$ & $F$ & $p$ \\
\hline \multirow[t]{2}{*}{1} & $B$ & 6,159 & 26.36 & $<0.0001$ & 2,159 & 192.6 & $<0.0001$ & 6,159 & 25.73 & $<0.0001$ \\
\hline & $c$ & 3,212 & 35.33 & $<0.0001$ & 3,212 & 99.48 & $<0.0001$ & 9,212 & 3.638 & 0.0003 \\
\hline \multirow{2}{*}{2} & $B$ & 3,156 & 9.559 & $<0.0001$ & 3,156 & 29.15 & $<0.0001$ & 9,156 & 0.7852 & 0.6303 \\
\hline & $C$ & 1,14 & 57.67 & $<0.0001$ & 1,14 & 87.57 & $<0.0001$ & 1,14 & 57.67 & $<0.0001$ \\
\hline 3 & $A$ & 3,126 & 22.16 & $<0.0001$ & 2,126 & 273 & $<0.0001$ & 6,126 & 22.48 & $<0.0001$ \\
\hline \multirow[t]{2}{*}{$3-1$} & $A$ & 3,135 & 119.8 & $<0.0001$ & 14,135 & 17.38 & $<0.0001$ & 42,135 & 6.527 & $<0.0001$ \\
\hline & $B$ & 3,126 & 1.69 & 0.1726 & 13,126 & 0.6727 & 0.7866 & 39,126 & 0.441 & 0.9979 \\
\hline \multirow[t]{3}{*}{4} & $A$ & 3,141 & 15.06 & $<0.0001$ & 2,141 & 108.9 & $<0.0001$ & 6,141 & 13.08 & $<0.0001$ \\
\hline & $B$ & 3,188 & 23.32 & $<0.0001$ & 3,188 & 52.63 & $<0.0001$ & 9,188 & 2.793 & 0.0043 \\
\hline & $C$ & 3,132 & 123.8 & $<0.0001$ & 7,132 & 4.318 & 0.0002 & 21,132 & 5.269 & $<0.0001$ \\
\hline \multirow[t]{3}{*}{5} & $B$, ipsilateral & 1,24 & 0.4318 & 0.5174 & 1,24 & 8.15 & 0.0087 & 1,24 & 8.15 & 0.0087 \\
\hline & $E$, ipsilateral & 1,24 & 0.012 & 0.9137 & 1,24 & 0.3846 & 0.5410 & 1,24 & 0.3846 & 0.5410 \\
\hline & $E$, contralateral & 1,24 & 3.895 & 0.0600 & 1,24 & 0.2506 & 0.6212 & 1,24 & 0.2506 & 0.6212 \\
\hline \multirow[t]{6}{*}{6} & $B$ & 1,40 & 14.69 & 0.0004 & 3,40 & 7.05 & 0.0006 & 3,40 & 2.229 & 0.997 \\
\hline & $C$ & 3,36 & 9.207 & 0.0001 & 1,36 & 0.2264 & 0.6371 & 3,36 & 0.85 & 0.4758 \\
\hline & $D, \operatorname{PrL}$ & 1,40 & 0.4426 & 0.8344 & 3,40 & 1.571 & 0.2115 & 3,40 & 0.4723 & 0.7033 \\
\hline & $E_{,} \mathrm{Cg} 1$ & 1,40 & 0.3194 & 0.5751 & 3,40 & 2.593 & 0.0660 & 3,40 & 0.1515 & 0.9281 \\
\hline & $F, G P$ & 3,36 & 9.207 & 0.0001 & 1,36 & 0.2264 & 0.6371 & 3,36 & 0.85 & 0.4758 \\
\hline & $G$, met & 5,60 & 12.19 & $<0.0001$ & 1,60 & 0.02826 & 0.8671 & 5,60 & 0.5204 & 0.7598 \\
\hline
\end{tabular}

${ }^{a} \mathrm{GP}$, Gabapentin; met, metformin.

cant portion of GABAergic cells in the $\mathrm{mPFC}$, and there is evidence that their function may be affected by both acute or chronic pain (Ji et al., 2010; Ji and Neugebauer, 2011; Zhang et al., 2015). Therefore, we next sought to determine whether SNI altered PV expression in areas of the frontal cortex. We performed a subregion-specific analysis of PV immunoreactivity in the IL and PrL regions of the $\mathrm{mPFC}$, as well as the Cg1 region in the hemispheres both ipsilateral (left) and contralateral (right) to the injured leg at 3 weeks after nerve injury (Fig. 5). PV-positive cell counts, which were normalized to DAPI in all experiments, were significantly reduced in the ipsilateral IL, and this effect was localized to lamina 5/6 (L5/6) in male mice (Fig. 5A,B). Given the sexual dimorphism in set-shifting performance between male and female SNI mice, we also assessed PV expression in females. Additionally, male and female SNI mice showed no significant differences in tactile allodynia (male SNI VF: $0.027 \pm 0.012$, female SNI VF: $0.036 \pm 0.013 ; p=0.9515)$. Female SNI and sham mice did not show any changes in PV expression in the IL (Fig. $5 C$ ). There were no changes in PV expression in the PrL (Fig. 5D) and Cg1 of male mice (Fig. $5 E$ ).

Gabapentin reversed the loss in PV expression (Fig. 5F), whereas metformin-treated SNI animals showed no significant difference relative to vehicle-treated SNI or sham control mice (Fig. 5G). We hypothesized that metformin's delayed action on pain resolution may explain its neutral effect on PV loss. In contrast to gabapentin, metformin restores mechanical withdrawal thresholds to baseline levels, even after the $7 \mathrm{~d}$ treatment period, an effect that has been shown to last up to several months after the end of drug treatment (Melemedjian et al., 2011; Shen et al., 2013; Melemedjian and Khoutorsky, 2015; Khoutorsky and Price, 2018). Therefore, we collected mPFC tissue from metformin and vehicle-treated animals $14 \mathrm{~d}$ after the 7 day treatment regimen. However, these animals still showed only a minor improvement in PV-positive cells relative to vehicle-treated SNI mice at the same time point (Fig. $5 G$ ).

\section{Metformin, but not gabapentin, reverses SNI-induced changes in AIS length in the infralimbic cortex}

Changes in AIS length have been linked to functional changes in neuronal excitability wherein AIS lengthen in response to deprivation of afferent input to the neuron and shorten in response to persistently augmented input (Grubb and Burrone, 2010; Kuba et al., 2010; Grubb et al., 2011). Given that persistent pain may dramatically alter inputs to the $\mathrm{mPFC}$, as has been observed in arthritic rats (Ji et al., 2010), we hypothesized that behavioral changes may be coupled to morphological reorganization of AISs in neuropathic pain. We assessed immunoreactivity for ankyrin-G, which labels the AIS (Jones and Svitkina, 2016; Leterrier, 2018), in laminas 2/3 (L2/3) and L5/6 within the subregions of the frontal cortex. SNI treatment in males significantly reduced AIS length in L5/6 of the ipsilateral (left) and contralateral (right) IL (Fig. 6A,B), but this effect was not apparent in female mice (Fig. 6C) who showed only a small SNI-induced deficit in attentional set-shifting. AIS length was not altered in the PrL (Fig. 6D) nor the Cg1 subregions of the medial frontal cortex (Fig. 6E).

Seven day gabapentin treatment had no effect on AIS length (Fig. 6F). On the other hand, 7 day metformin treatment (tissue collected $1 \mathrm{~d}$ after the end of treatment) reversed the AIS loss in the ipsilateral hemisphere, but not in the contralateral hemisphere (Fig. 6G). However, when tissue was collected $14 \mathrm{~d}$ after cessation of 7 day metformin treatment (to create a longer lasting pain relief), a complete restoration of AIS length was observed in both the ipsilateral and contralateral hemispheres of male mice (Fig. 6G). 
Table 2. Two-way ANOVA Bonferroni comparisons ${ }^{a}$

\begin{tabular}{|c|c|c|c|c|c|c|c|c|}
\hline Figure & Comparison & $p$ & Figure & Comparison & $p$ & Figure & Comparison & $p$ \\
\hline \multirow[t]{21}{*}{$1 B$} & Response & & $2 B$ & PE & & & Sham/gp versus $\mathrm{SNI} / \mathrm{gp}$ & 0.0308 \\
\hline & Male Sham versus female Sham & $>0.9999$ & & Sham/veh versus Sham/clonidine & $>0.9999$ & & SNI/veh versus SNI/gp & 0.6045 \\
\hline & Male Sham versus male SNI & $>0.9999$ & & Sham/veh versus SNI/veh & $>0.9999$ & & OE & \\
\hline & Male Sham versus female SNI & $>0.9999$ & & Sham/veh versus SNI/clonidine & $>0.9999$ & & Sham/veh versus Sham/gp & 0.0638 \\
\hline & Female Sham versus male SNI & $>0.9999$ & & Sham/clonidine versus SNI/veh & $>0.9999$ & & Sham/veh versus SNI/veh & 0.0023 \\
\hline & Female Sham versus female SNI & $>0.9999$ & & Sham/clonidine versus SNI/clonidine & $>0.9999$ & & Sham/veh versus SNI/gp & 0.0001 \\
\hline & Male SNI versus female SNI & 0.9606 & & SNI/veh versus SNI/clonidine & $>0.9999$ & & Sham/gp versus SNI/veh & $>0.9999$ \\
\hline & Retest & & & NRE & & & Sham/gp versus SNI/gp & $>0.9999$ \\
\hline & Male Sham versus female Sham & $>0.9999$ & & Sham/veh versus Sham/clonidine & $>0.9999$ & & SNI/veh versus SNI/gp & $>0.9999$ \\
\hline & Male Sham versus male SNI & $>0.9999$ & & Sham/veh versus SNI/veh & 0.0031 & $3 C$ & Sham/veh versus Sham/gp BL & $>0.9999$ \\
\hline & Male Sham versus female SNI & $>0.9999$ & & Sham/veh versus SNI/clonidine & 0.0484 & & Sham/veh versus SNI/gp BL & $>0.9999$ \\
\hline & Female Sham versus male SNI & $>0.9999$ & & Sham/clonidine versus SNI/veh & 0.9600 & & Sham/gp versus SNI/gp BL & $>0.9999$ \\
\hline & Female Sham versus female SNI & $>0.9999$ & & Sham/clonidine versus SNI/clonidine & $>0.9999$ & & Sham/veh versus Sham/gp 2 weeks & $<0.0001$ \\
\hline & Male SNI versus female SNI & $>0.9999$ & & SNI/veh versus SNI/clonidine & $>0.9999$ & & Sham/veh versus SNI/gp 2 weeks & $>0.9999$ \\
\hline & Set shifting & & & RE & & & Sham/gp versus SNI/gp 2 weeks & $<0.0001$ \\
\hline & Male Sham versus female Sham & 0.4802 & & Sham/veh versus Sham/clonidine & $>0.9999$ & & Sham/veh versus Sham/gp day 3 & $<0.0001$ \\
\hline & Male Sham versus male SNI & $<0.0001$ & & Sham/veh versus SNI/veh & 0.6474 & & Sham/veh versus SNI/gp day 3 & $<0.0001$ \\
\hline & Male Sham versus female SNI & 0.0443 & & Sham/veh versus SNI/clonidine & 0.1373 & & Sham/gp versus SNI/gp day 3 & 0.4812 \\
\hline & Female Sham versus male SNI & $<0.0001$ & & Sham/clonidine versus SNI/veh & $>0.9999$ & & Sham/veh versus Sham/gp day 7 & $<0.0001$ \\
\hline & Female Sham versus female SNI & 0.0246 & & Sham/clonidine versus SNI/clonidine & 0.5320 & & Sham/veh versus SNI/gp day 7 & $<0.0001$ \\
\hline & Male SNI versus female SNI & $<0.0001$ & & SNI/veh versus SNI/clonidine & $>0.9999$ & & Sham/gp versus SN1/gp day 7 & 0.9212 \\
\hline \multirow[t]{28}{*}{ ic } & PE & & & OE & & $4 A$ & Response & \\
\hline & Male Sham versus female Sham & $>0.9999$ & & Sham/veh versus Sham/clonidine & 0.7358 & & Sham/veh versus Sham/met & $>0.9999$ \\
\hline & Male Sham versus male SNI & 0.5887 & & Sham/veh versus SNI/veh & 0.0051 & & Sham/veh versus $\mathrm{SNI} /$ veh & $>0.9999$ \\
\hline & Male Sham versus female SNI & $>0.9999$ & & Sham/veh versus SNI/clonidine & 0.0173 & & Sham/veh versus SNI/met & $>0.9999$ \\
\hline & Female Sham versus male SNI & 0.2217 & & Sham/clonidine versus SNI/veh & $>0.9999$ & & Sham/met versus SNI/veh & $>0.9999$ \\
\hline & Female Sham versus female SNI & $>0.9999$ & & Sham/clonidine versus SNI/clonidine & $>0.9999$ & & Sham/met versus SNI/met & $>0.9999$ \\
\hline & Male SNI versus female SNI & 0.2217 & & SNI/veh versus SNI/clonidine & $>0.9999$ & & $\mathrm{SNI} /$ veh versus $\mathrm{SNI} / \mathrm{met}$ & $>0.9999$ \\
\hline & NRE & & $2 c$ & SNI/veh versus SNI/clonidine BL & $>0.9999$ & & Retest & \\
\hline & Male Sham versus female Sham & 0.3472 & & SNI/veh versus SNI/clonidine inj & $<0.0001$ & & Sham/veh versus Sham/met & $>0.9999$ \\
\hline & Male Sham versus male SNI & $<0.0001$ & $3 A$ & Response & & & Sham/veh versus SNI/veh & $>0.9999$ \\
\hline & Male Sham versus female SNI & $>0.9999$ & & Sham/veh versus Sham/gp & 0.8412 & & Sham/veh versus $\mathrm{SN} / / \mathrm{met}$ & $>0.9999$ \\
\hline & Female Sham versus male SNI & $<0.0001$ & & Sham/veh versus SNI/veh & $>0.9999$ & & Sham/met versus SNI/veh & $>0.9999$ \\
\hline & Female Sham versus female SNI & $>0.9999$ & & Sham/veh versus SNI/gp & $>0.9999$ & & Sham/met versus SNI/met & $>0.9999$ \\
\hline & Male SNI versus female SNI & $<0.0001$ & & Sham/gp versus SNI/veh & 0.3236 & & $\mathrm{SNI} /$ veh versus $\mathrm{SNI} / \mathrm{met}$ & $>0.9999$ \\
\hline & RE & & & Sham/gp versus SNI/gp & $>0.9999$ & & Set shifting & \\
\hline & Male Sham versus female Sham & $>0.9999$ & & SNI/veh versus SNI/gp & $>0.9999$ & & Sham/veh versus Sham/met & $>0.9999$ \\
\hline & Male Sham versus male SNI & 0.0792 & & Retest & & & Sham/veh versus SNI/veh & $<0.0001$ \\
\hline & Male Sham versus female SNI & $>0.9999$ & & Sham/veh versus Sham/gp & $>0.9999$ & & Sham/veh versus $\mathrm{SN} / / \mathrm{met}$ & 0.1152 \\
\hline & Female Sham versus male SNI & 0.0028 & & Sham/veh versus SNI/veh & $>0.9999$ & & Sham/met versus SNI/veh & $<0.0001$ \\
\hline & Female Sham versus female SNI & $>0.9999$ & & Sham/veh versus SNI/gp & $>0.9999$ & & Sham/met versus SNI/met & $>0.9999$ \\
\hline & Male SNI versus female SNI & 0.0052 & & Sham/gp versus SNI/veh & $>0.9999$ & & $\mathrm{SNI} /$ veh versus $\mathrm{SNI} / \mathrm{met}$ & $<0.0001$ \\
\hline & OE & & & Sham/gp versus SNI/gp & $>0.9999$ & $4 B$ & $\mathrm{PE}$ & \\
\hline & Male Sham versus female Sham & $>0.9999$ & & SNI/veh versus SNI/gp & $>0.9999$ & & Sham/veh versus Sham/met & $>0.9999$ \\
\hline & Male Sham versus male SNI & $<0.0001$ & & Set shifting & & & Sham/veh versus $\mathrm{SNI} /$ veh & 0.8697 \\
\hline & Male Sham versus female SNI & 0.0107 & & Sham/veh versus Sham/gp & 0.006 & & Sham/veh versus $\mathrm{SN} / / \mathrm{met}$ & $>0.9999$ \\
\hline & Female Sham versus male SNI & $<0.0001$ & & Sham/veh versus SNI/veh & $<0.0001$ & & Sham/met versus SNI/veh & $>0.9999$ \\
\hline & Female Sham versus female SNI & 0.0241 & & Sham/veh versus SNI/gp & $<0.0001$ & & Sham/met versus SNI/met & $>0.9999$ \\
\hline & Male SNI versus female SNI & 0.2543 & & Sham/gp versus SNI/veh & 0.0001 & & $\mathrm{SNI} /$ veh versus $\mathrm{SNI} / \mathrm{met}$ & 0.7763 \\
\hline \multirow[t]{21}{*}{$2 A$} & Response & & & Sham/gp versus SNI/gp & $<0.0001$ & & NRE & \\
\hline & Sham/veh versus Sham/clonidine & $>0.9999$ & & SNI/veh versus SNI/gp & 0.0002 & & Sham/veh versus Sham/met & 0.2788 \\
\hline & Sham/veh versus $\mathrm{SN} /$ veh & $>0.9999$ & $3 B$ & PE & & & Sham/veh versus SNI/veh & $<0.0001$ \\
\hline & Sham/veh versus SNI/clonidine & $>0.9999$ & & Sham/veh versus Sham/gp & $>0.9999$ & & Sham/veh versus $\mathrm{SN} / / \mathrm{met}$ & $>0.9999$ \\
\hline & Sham/clonidine versus SNI/veh & $>0.9999$ & & Sham/veh versus SNI/veh & $>0.9999$ & & Sham/met versus SNI/veh & $<0.0001$ \\
\hline & Sham/clonidine versus SNI/clonidine & $>0.9999$ & & Sham/veh versus SNI/gp & $>0.9999$ & & Sham/met versus SNI/met & $>0.9999$ \\
\hline & SNI/veh versus SNI/clonidine & $>0.9999$ & & Sham/gp versus SNI/veh & $>0.9999$ & & $\mathrm{SNI} /$ veh versus $\mathrm{SNI} / \mathrm{met}$ & $<0.0001$ \\
\hline & Retest & & & Sham/gp versus SNI/gp & $>0.9999$ & & RE & \\
\hline & Sham/veh versus Sham/clonidine & $>0.9999$ & & SNI/veh versus SNI/gp & $>0.9999$ & & Sham/veh versus Sham/met & $>0.9999$ \\
\hline & Sham/veh versus $\mathrm{SN} /$ veh & $>0.9999$ & & NRE & & & Sham/veh versus SNI/veh & 0.1732 \\
\hline & Sham/veh versus SNI/clonidine & $>0.9999$ & & Sham/veh versus Sham/gp & $>0.9999$ & & Sham/veh versus $\mathrm{SN} / / \mathrm{met}$ & $>0.9999$ \\
\hline & Sham/clonidine versus SNI/veh & $>0.9999$ & & Sham/veh versus SNI/veh & 0.0031 & & Sham/met versus SNI/veh & 0.1397 \\
\hline & Sham/clonidine versus SNI/clonidine & $>0.9999$ & & Sham/veh versus SNI/gp & $<0.0001$ & & Sham/met versus SNI/met & $>0.9999$ \\
\hline & SNI/veh versus SNI/clonidine & $>0.9999$ & & Sham/gp versus SNI/veh & 0.3038 & & $\mathrm{SNI} /$ veh versus $\mathrm{SNI} / \mathrm{met}$ & 0.1613 \\
\hline & Set shifting & & & Sham/gp versus SNI/gp & 0.0013 & & OE & \\
\hline & Sham/veh versus Sham/clonidine & 0.4802 & & SNI/veh versus SNI/gp & 0.0903 & & Sham/veh versus Sham/met & $>0.9999$ \\
\hline & Sham/veh versus SNI/veh & $<0.0001$ & & RE & & & Sham/veh versus $\mathrm{SNI} /$ veh & $<0.0001$ \\
\hline & Sham/veh versus SNI/clonidine & $<0.0001$ & & Sham/veh versus Sham/gp & $>0.9999$ & & Sham/veh versus $\mathrm{SN} / / \mathrm{met}$ & 0.4018 \\
\hline & Sham/clonidine versus SNI/veh & 0.0010 & & Sham/veh versus SNI/veh & 0.5220 & & Sham/met versus SNI/veh & 0.0990 \\
\hline & Sham/clonidine versus SNI/clonidine & 0.0056 & & Sham/veh versus SNI/gp & 0.0159 & & Sham/met versus SNI/met & $>0.9999$ \\
\hline & SNI/veh versus SNI/clonidine & $>0.9999$ & & Sham/gp versus SNI/veh & 0.6088 & & $\mathrm{SNI} /$ veh versus $\mathrm{SNI} / \mathrm{met}$ & 0.0188 \\
\hline
\end{tabular}

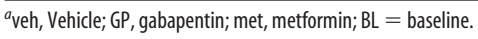


Table 3. Two-way ANOVA Bonferroni comparisons ${ }^{a}$

\begin{tabular}{|c|c|c|c|c|c|}
\hline Figure & Comparison & $p$ & Figure & Comparison & $p$ \\
\hline \multirow[t]{66}{*}{$4 C$} & Sham/veh versus Sham/met & $<0.9999$ & $5 B$, ipsilateral & L2/L3 ipsilateral Sham/veh versus SNI/veh, IL & 0.2666 \\
\hline & Sham/veh versus SNI/veh BL & 0.6866 & & L5/L6 ipsilateral Sham/veh versus SNI/veh ipsilateral, IL & 0.0408 \\
\hline & Sham/veh versus $\mathrm{SNI} / \mathrm{met} \mathrm{BL}$ & 0.5082 & $5 B$, contralateral & L2/L3 contralateral Sham/veh versus SNI/veh, IL & 0.7179 \\
\hline & Sham/met versus SNI/veh BL & $>0.9999$ & & L5/L6 contralateral Sham/veh versus SNI/veh contralateral, IL & 0.5994 \\
\hline & Sham/met versus SNI/met BL & $>0.9999$ & 5C, ipsilateral & L2/L3 ipsilateral Sham/veh versus SNI/veh, IL females & $>0.9999$ \\
\hline & $\mathrm{SNI} /$ veh versus $\mathrm{SNI} / \mathrm{met} \mathrm{BL}$ & $>0.9999$ & & L5/L6 ipsilateral Sham/veh versus SNI/veh contralateral, IL Fem & $>0.9999$ \\
\hline & Sham/veh versus Sham/met 14 & $>0.9999$ & $5 C$, contralateral & L2/L3 contralateral Sham/veh versus SNI/veh, IL females & 0.9271 \\
\hline & Sham/veh versus SNI/veh 14 & $<0.0001$ & & L5/L6 contralateral Sham/veh versus SNI/veh contralateral, IL & $>0.9999$ \\
\hline & Sham/veh versus SNI/met 14 & $<0.0001$ & $5 D$, ipsilateral & L2/L3 ipsilateral Sham/veh versus SNI/veh, PrL & 0.4175 \\
\hline & Sham/met versus SNI/veh 14 & $<0.0001$ & & L5/L6 ipsilateral Sham/veh versus SNI/veh contralateral, PrL & $>0.9999$ \\
\hline & Sham/met versus SNI/met 14 & $<0.0001$ & $5 D$, contralateral & L2/L3 contralateral Sham/veh versus SNI/veh, PrL & $>0.9999$ \\
\hline & SNI/veh versus SNI/met 14 & $>0.9999$ & & L5/L6 contralateral Sham/veh versus SNI/veh contralateral, PrL & $>0.9999$ \\
\hline & Sham/veh versus Sham/met 15 & $>0.9999$ & $5 E$, ipsilateral & L2/L3 ipsilateral Sham/veh versus SNI/veh, Cg1 & $>0.9999$ \\
\hline & Sham/veh versus SNI/veh 15 & $<0.0001$ & & L5/L6 ipsilateral Sham/veh versus SNI/veh contralateral, Cg1 & 0.9006 \\
\hline & Sham/veh versus SNI/met 15 & $<0.0001$ & $5 E$, contralateral & L2/L3 contralateral Sham/veh versus SNI/veh, Cg1 & 0.8647 \\
\hline & Sham/met versus SNI/veh 15 & $<0.0001$ & & $\mathrm{~L} 5 / \mathrm{L} 6$ contralateral Sham/veh versus SNI/veh contralateral, Cg1 & 0.3809 \\
\hline & Sham/met versus SNI/met 15 & $<0.0001$ & $6 B$ & L2/L3 ipsilateral Sham/veh versus SNI/veh, IL & 0.9231 \\
\hline & SNI/veh versus SNI/met 15 & 0.9150 & & L5/L6 ipsilateral Sham/veh versus SNI/veh ipsilateral, IL & 0.0067 \\
\hline & Sham/veh versus Sham/met 16 & $>0.9999$ & & L2/L3 contralateral Sham/veh versus SNI/veh, IL & $>0.9999$ \\
\hline & Sham/veh versus SNI/veh 16 & $<0.0001$ & & L5/L6 contralateral Sham/veh versus SNI/veh contralateral, IL & 0.0230 \\
\hline & Sham/veh versus SNI/met 16 & 0.0436 & $6 C$ & L2/L3 ipsilateral Sham/veh versus SNI/veh, IL & 0.0908 \\
\hline & Sham/met versus SNI/veh 16 & $<0.0001$ & & L5/L6 ipsilateral Sham/veh versus SNI/veh contralateral, IL & 0.7201 \\
\hline & Sham/met versus SNI/met 16 & 0.0090 & & L2/L3 contralateral Sham/veh versus SNI/veh, IL & 0.2153 \\
\hline & SNI/veh versus SNI/met 16 & 0.0043 & & L5/L6 contralateral Sham/veh versus SNI/veh contralateral, IL & 0.1695 \\
\hline & Sham/veh versus Sham/met 17 & $>0.9999$ & 60 & Sham/veh versus SNI/veh ipsilateral L2/L3, PrL & $>0.9999$ \\
\hline & Sham/veh versus SNI/veh 17 & $<0.0001$ & & Sham/veh versus SNI/veh ipsilateral L5/L6, PrL & $>0.9999$ \\
\hline & Sham/veh versus SNI/met 17 & $>0.9999$ & & Sham/veh versus SNI/veh contralateral L2/L3, PrL & $>0.9999$ \\
\hline & Sham/met versus SNI/veh 17 & $<0.0001$ & & Sham/veh versus SNI/veh contralateral L5/L6, PrL & $>0.9999$ \\
\hline & Sham/met versus SNI/met 17 & $>0.9999$ & $6 E$ & Sham/veh versus SNI/veh ipsilateral L2/L3, Cg1 & $>0.9999$ \\
\hline & SNI/veh versus SNI/met 17 & $<0.0001$ & & Sham/veh versus SNI/veh ipsilateral L5/L6, Cg1 & $>0.9999$ \\
\hline & Sham/veh versus Sham/met 18 & $>0.9999$ & & Sham/veh versus SNI/veh contralateral $\mathrm{L} 2 / \mathrm{L} 3, \mathrm{Cg} 1$ & $>0.9999$ \\
\hline & Sham/veh versus SNI/veh 18 & $<0.0001$ & & Sham/veh versus SNI/veh contralateral $\mathrm{L5} / \mathrm{L} 6, \mathrm{Cg} 1$ & $>0.9999$ \\
\hline & Sham/veh versus SNI/met 18 & 0.6051 & $6 F$ & L5/L6 ipsilateral: SNI/veh versus Sham/veh, IL & 0.0041 \\
\hline & Sham/met versus SNI/veh 18 & $<0.0001$ & & L5/L6 ipsilateral: SNI/veh versus Sham/gp, IL & 0.0134 \\
\hline & Sham/met versus SNI/met 18 & 0.4778 & & L5/L6 ipsilateral: SNI/veh versus SNI/gp, IL & $>0.9999$ \\
\hline & SNI/veh versus SNI/met 18 & $<0.0001$ & & L5/L6 contralateral: SNI/veh versus Sham/veh, IL & 0.0143 \\
\hline & Sham/veh versus Sham/met 19 & 0.3421 & & L5/L6 contralateral: SNI/veh versus Sham/gp, IL & $>0.9999$ \\
\hline & Sham/veh versus SNI/veh 19 & $<0.0001$ & & L5/L6 contralateral: SNI/veh versus SNI/gp, IL & $>0.9999$ \\
\hline & Sham/veh versus SNI/met 19 & $>0.9999$ & $6 G$ & L5/L6 ipsilateral: SNI/veh 1d versus Sham/veh, IL & 0.0014 \\
\hline & Sham/met versus SNI/veh 19 & $<0.0001$ & & L5/L6 ipsilateral: SNI/veh 1d versus Sham/met 1d, IL & 0.0058 \\
\hline & Sham/met versus SNI/met 19 & 0.4576 & & L5/L6 ipsilateral: SNI/veh 1d versus SNI/met 1d, IL & 0.0064 \\
\hline & SNI/veh versus SNI/met 19 & $<0.0001$ & & L5/L6 ipsilateral: SNI/veh 1d versus SNI/veh 14d, IL & $>0.9999$ \\
\hline & Sham/veh versus Sham/met 21 & $>0.9999$ & & L5/L6 ipsilateral: SNI/veh 1d versus SNI/met 14d, IL & 0.0036 \\
\hline & Sham/veh versus SNI/veh 21 & $<0.0001$ & & L5/L6 contralateral: SNI/veh 1d versus Sham/veh, IL & 0.0072 \\
\hline & Sham/veh versus SNI/met 21 & $>0.9999$ & & L5/L6 contralateral: SNI/veh 1d versus Sham/met 1d, IL & 0.0291 \\
\hline & Sham/met versus SNI/veh 21 & $<0.0001$ & & L5/L6 contralateral: SNI/veh 1d versus SNI/met 1d, IL & 0.9947 \\
\hline & Sham/met versus SNI/met 21 & $>0.9999$ & & L5/L6 contralateral: SNI/veh 1d versus SNI/veh 14d, IL & $>0.9999$ \\
\hline & SNI/veh versus SNI/met 21 & $<0.0001$ & & L5/L6 contralateral: SNI/veh 1d versus SNI/met 14d, IL & 0.0218 \\
\hline & & & $3-1 A$ & $\mathrm{BL}: \mathrm{SNI} /$ veh versus SNI/GP (100 mg/kg) & 0.7862 \\
\hline & & & SNI/gp 100 mg/kg comparison shown & NC 2 week: SNI/veh versus SNI/GP (100 mg/kg) & $>0.9999$ \\
\hline & & & & $30 \mathrm{~min}:$ SNI/veh versus SNI/GP $(100 \mathrm{mg} / \mathrm{kg})$ & 0.0083 \\
\hline & & & & $1 \mathrm{~h}: \mathrm{SNI} /$ veh versus SNI/GP (100 mg/kg) & $<0.0001$ \\
\hline & & & & $2 \mathrm{~h}:$ SNI/veh versus SNI/GP (100 mg/kg) & $<0.0001$ \\
\hline & & & & $3 \mathrm{~h}:$ SNI/veh versus SNI/GP (100 mg/kg) & $<0.0001$ \\
\hline & & & & $4 \mathrm{~h}: \mathrm{SNI} /$ veh versus SNI/GP $(100 \mathrm{mg} / \mathrm{kg})$ & $<0.0001$ \\
\hline & & & & $5 \mathrm{~h}: \mathrm{SNI} /$ veh versus SNI/GP $(100 \mathrm{mg} / \mathrm{kg})$ & $<0.0001$ \\
\hline & & & & $6 \mathrm{~h}:$ SNI/veh versus SNI/GP (100 mg/kg) & $<0.0001$ \\
\hline & & & & $6.5 \mathrm{~h}: \mathrm{SNI} / \mathrm{veh}$ versus SNI/GP $(100 \mathrm{mg} / \mathrm{kg})$ & 0.0645 \\
\hline & & & & $7 \mathrm{~h}: \mathrm{SNI} /$ veh versus SNI/GP (100 mg/kg) & 0.0919 \\
\hline & & & & $7.5 \mathrm{~h}:$ SNI/veh versus SNI/GP $(100 \mathrm{mg} / \mathrm{kg})$ & $>0.9999$ \\
\hline & & & $3-1 B$ & $\mathrm{BL}: \mathrm{SNI} / \mathrm{veh}$ versus SNI/GP (100 mg/kg) & $>0.9999$ \\
\hline & & & SNI/gp $100 \mathrm{mg} / \mathrm{kg}$ comparison shown & NC 2 week: SNI/veh versus SNI/GP $(100 \mathrm{mg} / \mathrm{kg})$ & $>0.9999$ \\
\hline & & & & $30 \mathrm{~min}: \mathrm{SNI} /$ veh versus SNI/GP (100 mg/kg) & $>0.9999$ \\
\hline & & & & $1 \mathrm{~h}:$ SNI/veh versus SNI/GP $(100 \mathrm{mg} / \mathrm{kg})$ & $>0.9999$ \\
\hline & & & & $2 \mathrm{~h}:$ SNI/veh versus SNI/GP (100 mg/kg) & $>0.9999$ \\
\hline & & & & & econtinues) \\
\hline
\end{tabular}




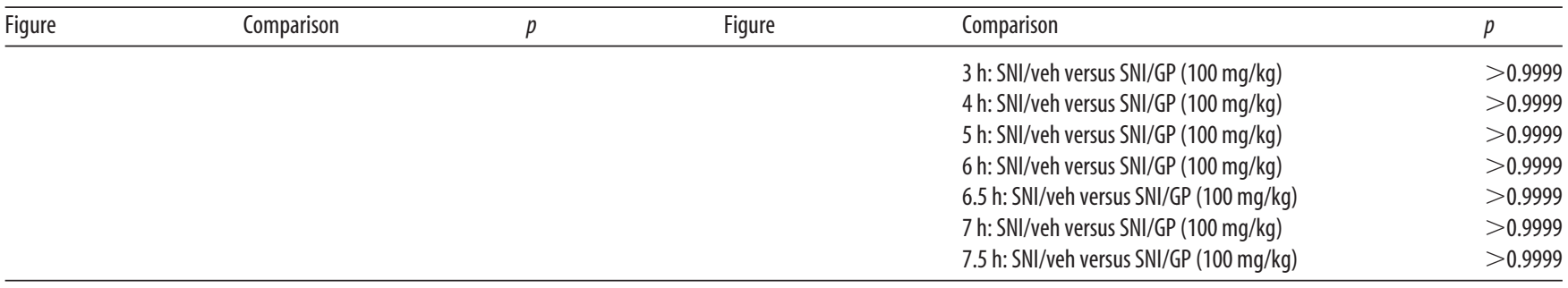

${ }^{a}$ veh, Vehicle; $\mathrm{GP}$, gabapentin; met, metformin; $\mathrm{NC}=$ neuropathic check.

Table 4. One-way ANOVA with Bonferroni ${ }^{a}$

\begin{tabular}{|c|c|c|c|c|c|c|c|c|}
\hline Figure & Panel & Between treatment (MS) & Within treatment (MS) & dfn,dfd & $F$ & $p$ & Comparison & $p$ \\
\hline 5 & $F$ & 2123 & 279.6 & 3,23 & 7.592 & 0.0011 & $\begin{array}{l}\text { SNI/veh versus Sham/veh } \\
\text { SNI/veh versus Sham/GP } \\
\text { SNI/veh versus SNI/GP }\end{array}$ & $\begin{array}{l}0.0088 \\
0.0047 \\
0.0006\end{array}$ \\
\hline 5 & $G$ & 1753 & 384.7 & 5,34 & 4.557 & 0.0027 & $\begin{array}{l}\text { SNI/veh versus Sham/veh } \\
\text { SNI/veh versus Sham/met } \\
\text { SNI/veh versus SNI/met 1d } \\
\text { SNI/veh } 1 \mathrm{~d} \text { versus SNI/veh 14d } \\
\text { SNI/veh } 1 \mathrm{~d} \text { versus SNI/met } 14\end{array}$ & $\begin{array}{r}0.0382 \\
0.0356 \\
0.8067 \\
>0.9999 \\
>0.9999\end{array}$ \\
\hline
\end{tabular}

${ }^{a}$ veh, Vehicle; GP, gabapentin; met, metformin.

\section{Discussion}

Chronic pain patients display frontal cortex-dependent cognitive deficits, even when taking commonly prescribed analgesics (Ryan et al., 1993; Eccleston, 1995; Karp et al., 2006; Dick and Rashiq, 2007; Schiltenwolf et al., 2014; Livingston-Thomas et al., 2015). Pain-induced structural and functional changes in the PFC (Metz et al., 2009; Ji et al., 2010; Blom et al., 2014; Zhang et al., 2015; Kelly et al., 2016) likely contribute to these impairments. However, the exact nature of these changes is still unknown, and it is unclear whether pain relief by existing therapeutics can reverse these changes. We assessed the impact of neuropathic pain and analgesics on behavioral and morphological measures of mPFC function in male and female mice. Neuropathic pain impaired attentional set-shifting, a task that in mice requires an intact mPFC (Birrell and Brown, 2000), in a sex-specific manner. The AMPK activator metformin reversed the deficits in male mice. Clonidine and gabapentin had no effect, mimicking findings from the clinical literature (Dick and Rashiq, 2007; Gálvez et al., 2007; Povedano et al., 2007; Schiltenwolf et al., 2014).

Importantly, transient pain relief with a single dose of clonidine was insufficient to alleviate SNI-induced deficits in setshifting. Based on this, we hypothesized that longer periods of pain relief are required to restore cognitive function. We used twice-daily injections of gabapentin to maintain pain relief and mimic human dosing regimens. However, gabapentin worsened set-shifting performance in both SNI and sham animals, indicating that the drug is inherently cognitively debilitating. Gabapentin is the most commonly prescribed analgesic for neuropathic pain despite its known side effects, which include drowsiness, confusion, and depression (Food and Drug Administration, 2011; Finnerup et al., 2015). A cross-sectional analysis of $>1500$ neuropathic pain patients revealed that, even after taking gabapentin for 3 months, patients still showed cognitive impairments, physical disability, and diminished quality of life (Gálvez et al., 2007; Povedano et al., 2007). Other commonly prescribed analgesics, such as opioids, produce similar side effects and are contraindicated for the management of pain and cognitive impairment (Schiltenwolf et al., 2014).
Metformin and other AMPK activators reduce thermal and mechanical hypersensitivity in rodents with neuropathic (Melemedjian et al., 2011; Mao-Ying et al., 2014; Melemedjian and Khoutorsky, 2015) and inflammatory pain (Burton et al., 2017), an effect that lasts several months. Metformin normalizes translation regulatory pathways, translation machinery, and sodium channel excitability in nociceptors (Melemedjian et al., 2011; Melemedjian and Khoutorsky, 2015), suggesting that nociceptors are a prime target of action. However, metformin has also been shown to have positive central effects as it enhances memory formation, neurogenesis, and angiogenesis in the brain (Wang et al., 2012; Kim et al., 2013; Venna et al., 2014). Metformin may also affect mPFC function through modulation of cholinergic activity. Acetylcholine release in the mPFC strongly modulates attention-demanding tasks (Passetti et al., 2000; Dalley et al., 2001; Parikh et al., 2007; Howe et al., 2013; Bloem et al., 2014; Naser and Kuner, 2017). SNI reduces M1-mediated depolarizing currents in L5 pyramidal cells, contributing to MPFC deactivation (Naser and Kuner, 2017; Radzicki et al., 2017). Acetylcholine activates AMPK in many cell types (Merlin et al., 2010; Kim et al., 2013; Lee and Choi, 2013; Zhao et al., 2013); thus, a loss of cholinergic activity could diminish AMPK activity in the mPFC. Conversely, AMPK activation has been shown to prevent memory deficits induced by the muscarinic receptor antagonist scopolamine and to protect against glutamatergic excitatory neurotoxicity in neurons (Kim et al., 2013). Therefore, metformin may restore cognitive function via AMPK activation in mPFC neurons. However, based on our data, we cannot differentiate whether metformin's effects on pain-induced cognitive dysfunction result from a direct action on nociceptors or on cortical circuitry.

Our work shows that neuropathic pain leads to a loss of PV expression in L5/6 of the IL ipsilateral to SNI. A loss of PV is found in several other disease pathologies, including schizophrenia, which are characterized by a loss of excitation-inhibition balance in the PFC and disruptions in executive functions. The loss of $\mathrm{PV}$ is thought to reflect persistent overstimulation of these cells by glutamatergic inputs (Behrens et al., 2007). However, it 
seems unlikely that the loss of PV in the IL is a hallmark of SNIinduced cognitive dysfunction because, even though gabapentin reversed the loss of PV, it still negatively affected behavioral outcomes. On the other hand, metformin treatment improved behavioral outcomes but did not rescue PV expression. Nevertheless, $\mathrm{PV}^{+}$interneurons likely play a key role in some painrelated cognitive impairments: In the mPFC, pain-induced changes in feedforward-inhibition cause deactivation of the PrL (Ji et al., 2010), and optogenetic activation of PV neurons in the PrL increases pain responses (Zhang et al., 2015).

SNI also reduced AIS length in L5/6 of the IL in male mice. Shortening of AIS may be a homeostatic mechanism to regulate network activity in situations where excitatory neurotransmission is enhanced (Grubb and Burrone, 2010; Kuba et al., 2010; Grubb et al., 2011). In a model of acute arthritis pain, projections from a hyperactivated BLA have previously been shown to cause PrL deactivation due to enhanced inhibition (Ji et al., 2010). However, the vast majority of BLA afferents to the PrL and the IL are onto pyramidal cells (Cheriyan et al., 2016), and BLA-evoked inhibitory responses are always disynaptic (Ji et al., 2010; Cheriyan et al., 2016). Thus, the SNI-induced reduction in AIS length in IL neurons may result from persistently enhanced glutamatergic inputs from upstream brain regions, including the BLA. Consistent with this idea, neuropathic pain was shown to reduce the intrinsic excitability of periaqueductal gray (PAG)-projecting pyramidal cells in the mPFC (Cheriyan and Sheets, 2018).

In addition to changes that emerge over time (acute vs chronic pain), some changes in synaptic plasticity may also be regionspecific. In rats with acute arthritic pain, excitatory transmission from putative BLA afferents in the PrL appeared to be unchanged (Ji et al., 2010). Consistent with this, we also saw no changes in AIS length in PrL neurons following SNI.

Importantly, gabapentin did not alter AIS length, whereas metformin normalized AIS length in the ipsilateral IL when assessed $1 \mathrm{~d}$ after treatment and in both hemispheres $14 \mathrm{~d}$ after treatment. Because metformin also rescued behavioral performance, this indicates that changes in AIS in the IL are correlated to cognitive dysfunction in neuropathic pain. Such decreases in AIS length, coupled with changes in dendritic spine density that have been described previously, may contribute to reductions in prefrontal cortical gray matter seen in human chronic pain patients (Apkarian et al., 2004; Schmidt-Wilcke et al., 2005; Kuchinad et al., 2007; Davis et al., 2008; Geha et al., 2008; Rodriguez-Raecke et al., 2009) and in SNI rats (Seminowicz et al., 2009).

In addition to disruptions in cognitive processing, the changes in AIS length may also implicate a dysfunctional PFC regulation of the emotional or sensory components of pain via descending projections to the amygdala and PAG, respectively (Berretta et al., 2005; Ferreira et al., 2015; Cheriyan et al., 2016; David-Pereira et al., 2016; Kiritoshi and Neugebauer, 2018). Regulation of the central nucleus of the amygdala via a projection from the IL to the intercalated cells (Berretta et al., 2005; Amir et al., 2011) is impaired in arthritic rats (Kiritoshi and Neugebauer, 2018). Similarly, neuropathic pain reduces the intrinsic excitability and excitatory inputs onto IL-PAG projection neurons (Cheriyan and Sheets, 2018), likely modulating the descending pain system (Ferreira et al., 2015).

Finally, we observed a sexual dimorphism in mPFC dysfunction in neuropathic mice. Although exploring sexual dimorphisms was not a main objective of the current study, the finding is compelling given known sex differences in chronic pain (Mogil and Bailey, 2010). Male SNI mice displayed a robust deficit in set-shifting performance coupled with a loss of PV expression and AIS length in the IL. In contrast, female SNI mice were less impaired and showed no change in PV expression nor AIS length. While sexual dimorphisms in cognitive flexibility have been observed in developmental and endocrinological studies, this is the first description of a sexual dimorphism in cognitive dysfunction in a rodent chronic pain model. However, in models of acute and chronic stress, similar changes were found, with stressed males showing stronger deficits in cognitive flexibility compared with females (Laredo et al., 2015; Shields et al., 2016). Stressed male rats also show a reduction in synapses and myelinated axons in the deeper cortical laminae of IL (Csabai et al., 2018). Therefore, it is possible that pain-induced stress contributes to our structural observations in this study. Recent findings have suggested that stress may cause downregulation of $\mu$-opioid receptor signaling in the brains of males but not females (Laredo et al., 2015). Likewise, differences in the maturation of the mPFC during adolescence may impart differential vulnerabilities to stressors, such as neuropathic pain in males and females during adulthood (Shansky et al., 2004; Lin et al., 2009; Willing and Juraska, 2015; Drzewiecki et al., 2016).

Our findings indicate that metformin alleviates neuropathic pain and cognitive deficits, suggesting that AMPK activators should be pursued for the management of chronic pain.

\section{References}

Amir A, Amano T, Pare D (2011) Physiological identification and infralimbic responsiveness of rat intercalated amygdala neurons. J Neurophysiol 105:3054-3066. CrossRef Medline

Apkarian AV, Sosa Y, Sonty S, Levy RM, Harden RN, Parrish TB, Gitelman DR (2004) Chronic back pain is associated with decreased prefrontal and thalamic gray matter density. J Neurosci 24:10410-10415. CrossRef Medline

Attal N, Masselin-Dubois A, Martinez V, Jayr C, Albi A, Fermanian J, Bouhassira D, Baudic S (2014) Does cognitive functioning predict chronic pain? Results from a prospective surgical cohort. Brain J Neurol 137:904917. CrossRef Medline

Behrens MM, Ali SS, Dao DN, Lucero J, Shekhtman G, Quick KL, Dugan LL (2007) Ketamine-induced loss of phenotype of fast-spiking interneurons is mediated by NADPH-oxidase. Science 318:1645-1647. CrossRef Medline

Berretta S, Pantazopoulos H, Caldera M, Pantazopoulos P, Paré D (2005) Infralimbic cortex activation increases c-fos expression in intercalated neurons of the amygdala. Neuroscience 132:943-953. CrossRef Medline

Birrell JM, Brown VJ (2000) Medial frontal cortex mediates perceptual attentional set-shifting in the rat. J Neurosci 20:4320-4324. CrossRef Medline

Bloem B, Poorthuis RB, Mansvelder HD (2014) Cholinergic modulation of the medial prefrontal cortex: the role of nicotinic receptors in attention and regulation of neuronal activity. Front Neural Circuits 8:17. CrossRef Medline

Blom SM, Pfister JP, Santello M, Senn W, Nevian T (2014) Nerve injuryinduced neuropathic pain causes disinhibition of the anterior cingulate cortex. J Neurosci 34:5754-5764. CrossRef Medline

Burton MD, Tillu DV, Mazhar K, Mejia GL, Asiedu MN, Inyang K, Hughes T, Lian B, Dussor G, Price TJ (2017) Pharmacological activation of AMPK inhibits incision-evoked mechanical hypersensitivity and the development of hyperalgesic priming in mice. Neuroscience 359:119-129. CrossRef Medline

Chaplan SR, Bach FW, Pogrel JW, Chung JM, Yaksh TL (1994) Quantitative assessment of tactile allodynia in the rat paw. J Neurosci Methods 53:5563. CrossRef Medline

Cheriyan J, Sheets PL (2018) Altered excitability and local connectivity of mPFC-PAG neurons in a mouse model of neuropathic pain. J Neurosci 38:4829-4839. CrossRef Medline

Cheriyan J, Kaushik MK, Ferreira AN, Sheets PL (2016) Specific targeting of the basolateral amygdala to projectionally defined pyramidal neurons in prelimbic and infralimbic cortex. eNeuro 3:ENEURO.0002-16-2016. CrossRef Medline

Csabai D, Wiborg O, Czéh B (2018) Reduced synapse and axon numbers in 
the prefrontal cortex of rats subjected to a chronic stress model for depression. Front Cell Neurosci 12:24. CrossRef Medline

Dalley JW, McGaughy J, O'Connell MT, Cardinal RN, Levita L, Robbins TW (2001) Distinct changes in cortical acetylcholine and noradrenaline efflux during contingent and noncontingent performance of a visual attentional task. J Neurosci 21:4908-4914. CrossRef Medline

David-Pereira A, Puga S, Gonçalves S, Amorim D, Silva C, Pertovaara A, Almeida A, Pinto-Ribeiro F (2016) Metabotropic glutamate 5 receptor in the infralimbic cortex contributes to descending pain facilitation in healthy and arthritic animals. Neuroscience 312:108-119. CrossRef Medline

Davis KD, Pope G, Chen J, Kwan CL, Crawley AP, Diamant NE (2008) Cortical thinning in IBS: implications for homeostatic, attention, and pain processing. Neurology 70:153-154. CrossRef Medline

Deacon RM (2013) Measuring motor coordination in mice. J Vis Exp 75: e2609. CrossRef Medline

Decosterd I, Woolf CJ (2000) Spared nerve injury: an animal model of persistent peripheral neuropathic pain. Pain 87:149-158. CrossRef Medline

Dick BD, Rashiq S (2007) Disruption of attention and working memory traces in individuals with chronic pain. Anesth Analg 104:1223-1229. CrossRef Medline

Dick B, Eccleston C, Crombez G (2002) Attentional functioning in fibromyalgia, rheumatoid arthritis, and musculoskeletal pain patients. Arthritis Rheum 47:639-644. CrossRef Medline

Drzewiecki CM, Willing J, Juraska JM (2016) Synaptic number changes in the medial prefrontal cortex across adolescence in male and female rats: a role for pubertal onset. Puberty and synaptic pruning in the MPFC. Synapse 70:361-368. CrossRef Medline

Eccleston C (1995) Chronic pain and distraction: an experimental investigation into the role of sustained and shifting attention in the processing of chronic persistent pain. Behav Res Ther 33:391-405. CrossRef Medline

Ferreira AN, Yousuf H, Dalton S, Sheets PL (2015) Highly differentiated cellular and circuit properties of infralimbic pyramidal neurons projecting to the periaqueductal gray and amygdala. Front Cell Neurosci 9:161. CrossRef Medline

Filice F, Vörckel KJ, Sungur AÖ, Wöhr M, Schwaller B (2016) Reduction in parvalbumin expression not loss of the parvalbumin-expressing GABA interneuron subpopulation in genetic parvalbumin and shank mouse models of autism. Mol Brain 9:10. CrossRef Medline

Finnerup NB, Attal N, Haroutounian S, McNicol E, Baron R, Dworkin RH, Gilron I, Haanpää M, Hansson P, Jensen TS, Kamerman PR, Lund K, Moore A, Raja SN, Rice AS, Rowbotham M, Sena E, Siddall P, Smith BH, Wallace M (2015) Pharmacotherapy for neuropathic pain in adults: a systematic review and meta-analysis. Lancet Neurol 14:162-173. CrossRef Medline

Food and Drug Administration (2011) Neurontin (gabapentin): FDAapproved labeling text. https://www.fda.gov/.

Franklin KBJ, Paxinos G (2008) The mouse brain in stereotaxic coordinates, Ed 3. Amsterdam, the Netherlands: Elsevier, AP.

Gálvez R, Marsal C, Vidal J, Ruiz M, Rejas J (2007) Cross-sectional evaluation of patient functioning and health-related quality of life in patients with neuropathic pain under standard care conditions. Eur J Pain 11:244255. CrossRef Medline

Geha PY, Baliki MN, Harden RN, Bauer WR, Parrish TB, Apkarian AV (2008) The brain in chronic CRPS pain: abnormal gray-white matter interactions in emotional and autonomic regions. Neuron 60:570-581. CrossRef Medline

Grubb MS, Burrone J (2010) Activity-dependent relocation of the axon initial segment fine-tunes neuronal excitability. Nature 465:1070-1074. CrossRef Medline

Grubb MS, Shu Y, Kuba H, Rasband MN, Wimmer VC, Bender KJ (2011) Short- and long-term plasticity at the axon initial segment. J Neurosci 31:16049-16055. CrossRef Medline

Hashemi E, Ariza J, Rogers H, Noctor SC, Martínez-Cerdeño V (2017) The number of parvalbumin-expressing interneurons is decreased in the medial prefrontal cortex in autism. Cereb Cortex 27:1931-1943. CrossRef Medline

Heisler JM, Morales J, Donegan JJ, Jett JD, Redus L, O’Connor JC (2015) The attentional set-shifting task: a measure of cognitive flexibility in mice. J Vis Exp 4:96. CrossRef Medline

Howe WM, Berry AS, Francois J, Gilmour G, Carp JM, Tricklebank M, Lustig C, Sarter M (2013) Prefrontal cholinergic mechanisms instigating shifts from monitoring for cues to cue-guided performance: converging electrochemical and fMRI evidence from rats and humans. J Neurosci 33: 8742-8752. CrossRef Medline

Hu W, Morris B, Carrasco A, Kroener S (2015) Effects of acamprosate on attentional set-shifting and cellular function in the prefrontal cortex of chronic alcohol-exposed mice. Alcohol Clin Exp Res 39:953-961. CrossRef Medline

Jeevakumar V, Driskill C, Paine A, Sobhanian M, Vakil H, Morris B, Ramos J, Kroener S (2015) Ketamine administration during the second postnatal week induces enduring schizophrenia-like behavioral symptoms and reduces parvalbumin expression in the medial prefrontal cortex of adult mice. Behav Brain Res 282:165-175. CrossRef Medline

Ji G, Neugebauer V (2011) Pain-related deactivation of medial prefrontal cortical neurons involves mGluR1 and GABA(A) receptors. J Neurophysiol 106:2642-2652. CrossRef Medline

Ji G, Sun H, Fu Y, Li Z, Pais-Vieira M, Galhardo V, Neugebauer V (2010) Cognitive impairment in pain through amygdala-driven prefrontal cortical deactivation. J Neurosci 30:5451-5464. CrossRef Medline

Jones SL, Svitkina TM (2016) Axon initial segment cytoskeleton: architecture, development, and role in neuron polarity. Neural Plast 2016:1-19. CrossRef Medline

Karp JF, Reynolds CF 3rd, Butters MA, Dew MA, Mazumdar S, Begley AE, Lenze E, Weiner DK (2006) The relationship between pain and mental flexibility in older adult pain clinic patients. Pain Med 7:444-452. CrossRef Medline

Kelly CJ, Huang M, Meltzer H, Martina M (2016) Reduced glutamatergic currents and dendritic branching of layer 5 pyramidal cells contribute to medial prefrontal cortex deactivation in a rat model of neuropathic pain. Front Cell Neurosci 10:133. CrossRef Medline

Khoutorsky A, Price TJ (2018) Translational control mechanisms in persistent pain. Trends Neurosci 41:100-114. CrossRef Medline

Kim SJ, Lee JH, Chung HS, Song JH, Ha J, Bae H (2013) Neuroprotective effects of AMP-activated protein kinase on scopolamine induced memory impairment. Korean J Physiol Pharmacol 17:331-338. CrossRef Medline

King T, Vera-Portocarrero L, Gutierrez T, Vanderah TW, Dussor G, Lai J, Fields HL, Porreca F (2009) Unmasking the tonic-aversive state in neuropathic pain. Nat Neurosci 12:1364-1366. CrossRef Medline

Kiritoshi T, Neugebauer V (2018) Pathway-specific alterations of corticoamygdala transmission in an arthritis pain model. ACS Chem Neurosci. Advance online publication. Retrieved Apr. 13, 2018. doi: 10.1021/ acschemneuro.8b00022. CrossRef Medline

Kuba H, Oichi Y, Ohmori H (2010) Presynaptic activity regulates $\mathrm{Na}^{+}$ channel distribution at the axon initial segment. Nature 465:1075-1078. CrossRef Medline

Kuchinad A, Schweinhardt P, Seminowicz DA, Wood PB, Chizh BA, Bushnell MC (2007) Accelerated brain gray matter loss in fibromyalgia patients: premature aging of the brain? J Neurosci 27:4004-4007. CrossRef Medline

Laredo SA, Steinman MQ, Robles CF, Ferrer E, Ragen BJ, Trainor BC (2015) Effects of defeat stress on behavioral flexibility in males and females: modulation by the mu-opioid receptor. Eur J Neurosci 41:434-441. CrossRef Medline

Lee KY, Choi HC (2013) Acetylcholine-induced AMP-activated protein kinase activation attenuates vasoconstriction through an LKB1-dependent mechanism in rat aorta. Vascul Pharmacol 59:96-102. CrossRef Medline

Leterrier C (2018) The axon initial segment: an updated viewpoint. J Neurosci 38:2135-2145. CrossRef Medline

Lin Y, Ter Horst GJ, Wichmann R, Bakker P, Liu A, Li X, Westenbroek C (2009) Sex differences in the effects of acute and chronic stress and recovery after long-term stress on stress-related brain regions of rats. Cereb Cortex 19:1978-1989. CrossRef Medline

Livingston-Thomas JM, Jeffers MS, Nguemeni C, Shoichet MS, Morshead CM, Corbett D (2015) Assessing cognitive function following medial prefrontal stroke in the rat. Behav Brain Res 294:102-110. CrossRef Medline

Mao-Ying QL, Kavelaars A, Krukowski K, Huo XJ, Zhou W, Price TJ, Cleeland C, Heijnen CJ (2014) The anti-diabetic drug metformin protects against chemotherapy-induced peripheral neuropathy in a mouse model. PLoS One 9:e100701. CrossRef Medline

Melemedjian OK, Khoutorsky A (2015) Translational control of chronic pain. Prog Mol Biol Transl Sci 131:185-213. CrossRef Medline

Melemedjian OK, Asiedu MN, Tillu DV, Sanoja R, Yan J, Lark A, Khoutorsky 
A, Johnson J, Peebles KA, Lepow T, Sonenberg N, Dussor G, Price TJ (2011) Targeting adenosine monophosphate-activated protein kinase (AMPK) in preclinical models reveals a potential mechanism for the treatment of neuropathic pain. Mol Pain 7:70. CrossRef Medline

Melemedjian OK, Yassine HN, Shy A, Price TJ (2013) Proteomic and functional annotation analysis of injured peripheral nerves reveals ApoE as a protein upregulated by injury that is modulated by metformin treatment. Mol Pain 9:14. CrossRef Medline

Merlin J, Evans BA, Csikasz RI, Bengtsson T, Summers RJ, Hutchinson DS (2010) The M3-muscarinic acetylcholine receptor stimulates glucose uptake in L6 skeletal muscle cells by a CaMKK-AMPK-dependent mechanism. Cell Signal 22:1104-1113. CrossRef Medline

Metz AE, Yau HJ, Centeno MV, Apkarian AV, Martina M (2009) Morphological and functional reorganization of rat medial prefrontal cortex in neuropathic pain. Proc Natl Acad Sci U S A 106:2423-2428. CrossRef Medline

Mogil JS, Bailey AL (2010) Sex and gender differences in pain and analgesia. Prog Brain Res 186:141-157. CrossRef Medline

Murray AJ, Woloszynowska-Fraser MU, Ansel-Bollepalli L, Cole KL, Foggetti A, Crouch B, Riedel G, Wulff P (2015) Parvalbumin-positive interneurons of the prefrontal cortex support working memory and cognitive flexibility. Sci Rep 5:16778. CrossRef Medline

Naser PV, Kuner R (2017) Molecular, cellular and circuit basis of cholinergic modulation of pain. Neuroscience. Advance online publication. Retrieved Sep. 8. 2018. doi: 10.1016/j.neuroscience.2017.08.049. CrossRef Medline

Parikh V, Kozak R, Martinez V, Sarter M (2007) Prefrontal acetylcholine release controls cue detection on multiple timescales. Neuron 56:141154. CrossRef Medline

Passetti F, Dalley JW, O'Connell MT, Everitt BJ, Robbins TW (2000) Increased acetylcholine release in the rat medial prefrontal cortex during performance of a visual attentional task: cortical ACh and attention. Eur J Neurosci 12:3051-3058. CrossRef Medline

Petitjean H, Pawlowski SA, Fraine SL, Sharif B, Hamad D, Fatima T, Berg J, Brown CM, Jan LY, Ribeiro-da-Silva A, Braz JM, Basbaum AI, SharifNaeini R (2015) Dorsal horn parvalbumin neurons are gate-keepers of touch-evoked pain after nerve injury. Cell Rep 13:1246-1257. CrossRef Medline

Phensy A, Driskill C, Lindquist K, Guo L, Jeevakumar V, Fowler B, Du H, Kroener S (2017a) Antioxidant treatment in male mice prevents mitochondrial and synaptic changes in an NMDA receptor dysfunction model of schizophrenia. eNeuro 4:ENEURO.0081-17.2017. CrossRef Medline

Phensy A, Duzdabanian HE, Brewer S, Panjabi A, Driskill C, Berz A, Peng G, Kroener S (2017b) Antioxidant treatment with N-acetyl cysteine prevents the development of cognitive and social behavioral deficits that result from perinatal ketamine treatment. Front Behav Neurosci 11:106. CrossRef Medline

Povedano M, Gascón J, Gálvez R, Ruiz M, Rejas J (2007) Cognitive function impairment in patients with neuropathic pain under standard conditions of care. J Pain Symptom Manage 33:78-89. CrossRef Medline

Radzicki D, Pollema-Mays SL, Sanz-Clemente A, Martina M (2017) Loss of M1 receptor dependent cholinergic excitation contributes to mPFC deactivation in neuropathic pain. J Neurosci 37:2292-2304. CrossRef Medline

Rodriguez-Raecke R, Niemeier A, Ihle K, Ruether W, May A (2009) Brain gray matter decrease in chronic pain is the consequence and not the cause of pain. J Neurosci 29:13746-13750. CrossRef Medline

Ryan CM, Williams TM, Finegold DN, Orchard TJ (1993) Cognitive dysfunction in adults with type 1 (insulin-dependent) diabetes mellitus of long duration: effects of recurrent hypoglycaemia and other chronic complications. Diabetologia 36:329-334. CrossRef Medline

Schiltenwolf M, Akbar M, Hug A, Pfüller U, Gantz S, Neubauer E, Flor H,
Wang H (2014) Evidence of specific cognitive deficits in patients with chronic low back pain under long-term substitution treatment of opioids. Pain Physician 17:9-20. Medline

Schmidt-Wilcke T, Leinisch E, Straube A, Kämpfe N, Draganski B, Diener HC, Bogdahn U, May A (2005) Gray matter decrease in patients with chronic tension type headache. Neurology 65:1483-1486. CrossRef Medline

Seminowicz DA, Laferriere AL, Millecamps M, Yu JS, Coderre TJ, Bushnell MC (2009) MRI structural brain changes associated with sensory and emotional function in a rat model of long-term neuropathic pain. Neuroimage 47:1007-1014. CrossRef Medline

Shansky RM, Glavis-Bloom C, Lerman D, McRae P, Benson C, Miller K, Cosand L, Horvath TL, Arnsten AF (2004) Estrogen mediates sex differences in stress-induced prefrontal cortex dysfunction. Mol Psychiatry 9:531-538. CrossRef Medline

Sheahan TD, Siuda ER, Bruchas MR, Shepherd AJ, Mohapatra DP, Gereau RW 4th, Golden JP (2017) Inflammation and nerve injury minimally affect mouse voluntary behaviors proposed as indicators of pain. Neurobiol Pain 2:1-12. CrossRef Medline

Shen CH, Yuan P, Perez-Lorenzo R, Zhang Y, Lee SX, Ou Y, Asara JM, Cantley LC, Zheng B (2013) Phosphorylation of BRAF by AMPK impairs BRAF-KSR1 association and cell proliferation. Mol Cell 52:161-172. CrossRef Medline

Shields GS, Trainor BC, Lam JC, Yonelinas AP (2016) Acute stress impairs cognitive flexibility in men, not women. Stress 19:542-546. CrossRef Medline

Urban R, Scherrer G, Goulding EH, Tecott LH, Basbaum AI (2011) Behavioral indices of ongoing pain are largely unchanged in male mice with tissue or nerve injury-induced mechanical hypersensitivity: Pain 152: 990-1000. CrossRef

Venna VR, Li J, Hammond MD, Mancini NS, McCullough LD (2014) Chronic metformin treatment improves post-stroke angiogenesis and recovery after experimental stroke. Eur J Neurosci 39:2129-2138. CrossRef Medline

Volman V, Behrens MM, Sejnowski TJ (2011) Downregulation of parvalbumin at cortical GABA synapses reduces network gamma oscillatory activity. J Neurosci 31:18137-18148. CrossRef Medline

Vreugdenhil M, Jefferys JG, Celio MR, Schwaller B (2003) Parvalbumin deficiency facilitates repetitive IPSCs and gamma oscillations in the hippocampus. J Neurophysiol 89:1414-1422. CrossRef Medline

Wang J, Gallagher D, DeVito LM, Cancino GI, Tsui D, He L, Keller GM, Frankland PW, Kaplan DR, Miller FD (2012) Metformin activates an atypical PKC-CBP pathway to promote neurogenesis and enhance spatial memory formation. Cell Stem Cell 11:23-35. CrossRef Medline

Wilcox GL, Carlsson KH, Jochim A, Jurna I (1987) Mutual potentiation of antinociceptive effects of morphine and clonidine on motor and sensory responses in rat spinal cord. Brain Res 405:84-93. CrossRef Medline

Willing J, Juraska JM (2015) The timing of neuronal loss across adolescence in the medial prefrontal cortex of male and female rats. Neuroscience 301:268-275. CrossRef Medline

Zhang Z, Gadotti VM, Chen L, Souza IA, Stemkowski PL, Zamponi GW (2015) Role of prelimbic GABAergic circuits in sensory and emotional aspects of neuropathic pain. Cell Rep 12:752-759. CrossRef Medline

Zhao M, Sun L, Yu XJ, Miao Y, Liu JJ, Wang H, Ren J, Zang WJ (2013) Acetylcholine mediates AMPK-dependent autophagic cytoprotection in $\mathrm{H} 9 \mathrm{c} 2$ cells during hypoxia/reoxygenation injury. Cell Physiol Biochem 32:601-613. CrossRef Medline

Zhou Z, Zhang G, Li X, Liu X, Wang N, Qiu L, Liu W, Zuo Z, Yang J (2015) Loss of phenotype of parvalbumin interneurons in rat prefrontal cortex is involved in antidepressant- and propsychotic-like behaviors following acute and repeated ketamine administration. Mol Neurobiol 51:808819. CrossRef Medline 